\title{
Habitat use, vertical and horizontal behaviour of Atlantic bluefin tuna (Thunnus thynnus) in the Northwestern Mediterranean Sea in relation to oceanographic conditions
}

\author{
Bauer R.K. ${ }^{1}$, Fromentin Jean-Marc ${ }^{1,{ }^{*} \text {, Demarcq Hervé }}{ }^{2}$, Bonhommeau Sylvain ${ }^{1}$
}

\author{
${ }^{1}$ IFREMER, UMR Marbec, Avenue Jean Monnet, CS 30171, 34203 Sète Cedex, France \\ 2 IRD, UMR Marbec, Avenue Jean Monnet, CS 30171, 34203 Sète Cedex, France \\ *Corresponding author : Jean-Marc Fromentin, email addresses : rbauer@gmx.com ; \\ robert.bauer@ifremer.fr
}

\begin{abstract}
:
We investigated the habitat utilization, vertical and horizontal behaviour of Atlantic bluefin tuna Thunnus thynnus (ABFT) in relation to oceanographic conditions in the northwestern Mediterranean Sea, based on 36 pop-up archival tags and different environmental data sets. Tags were deployed on early mature ABFT (127-255 cm) between July and November in 2007-2014, on the shelf area off Marseille, France. The data obtained from these tags provided 1643 daily summaries of ABFT vertical behaviour over 8 years of tag deployment. Based on a hierarchical clustering of this data, we could identify four principle daily vertical behaviour types, representing surface $(\leqq 10 \mathrm{~m})$ and subsurface $(10-100 \mathrm{~m})$ orientation, moderate $(50-200 \mathrm{~m})$ and deep $(\geqq 200 \mathrm{~m})$ diving behaviour. These vertical behaviour types showed seasonal variations with partly opposing trends in their frequencies. Accordingly, ABFT were more surface orientated during summer, while moderate diving behaviour was more common during winter. Depth time series data further revealed inverted day-night patterns for both of these periods. Tagged ABFT frequented the surface waters more regularly during daytime and deeper waters during the night in summer, while the opposite pattern was found in winter. Seasonal changes in the vertical behaviour of ABFT were accompanied by simultaneous changes in environmental conditions (SST, chla, thermal stratification). Accordingly, surface orientation and moderate diving behaviour appeared to be triggered by the thermal stratification of the water column, though less pronounced than previously reported for ABFT in the North Atlantic, probably indicating adaptive vertical behaviour related to the availability of epipelagic food resources (anchovies and sardines). Deep diving behaviour was particularly frequent during months of high biological productivity (February-May), although one recovered tag showed periodic and unusual long spike dives during summer-autumn, in relation to thermal fronts. Regional effects on the vertical behaviour of ABFT were identified through GAMs, with surface orientation being particularly pronounced in the Gulf of Lions, highlighting its suitability for an ongoing annual aerial survey program to estimate ABFT abundance in this region. In addition, increased levels of mesoscale activity/productivity (e.g. related to oceanic fronts) were detected in an area regularly utilized by ABFT, south of the Gulf of Lions, underlining its attractiveness as foraging ground. Kernel densities of geolocation estimates showed a seasonal shift in the horizontal distribution of ABFT from this "high-use" area towards the Gulf of Lions during summer, probably linked to the enhanced
\end{abstract}


availability of epipelagic food resources at this time.

Keywords : Thunnus thynnus, Habitat use, Spike dives, Fronts, Thermal stratification, Archival tags 


\section{${ }_{42} \mathbf{1}$ Introduction}

43 Several tagging experiments have revealed that Atlantic bluefin tuna Thunnus thynnus

${ }_{44}$ (ABFT) conduct large scale migrations throughout the North Atlantic, but also highlighted

45 their site fidelity to two distinct spawning areas, the Gulf of Mexico and the Mediterranean

46 Sea (e.g. Block et al., 2005, see Fromentin and Powers, 2005 for a review). These

47 results led to the assumption of two separate spawning stocks that overlap in their

48 distributions on North Atlantic feeding grounds (Block et al., 2005). While this concept

49 is widely accepted nowadays, the actual population structure and habitat use of ABFT

${ }_{50}$ requires better understanding. In this context, Fromentin and Powers (2005) advocated

${ }_{51}$ a meta-population hypothesis, according to which, several distinct ABFT subpopulations

52 may exist that could differ in their habitat use and migratory behaviour. In fact, different

53 spawning sites of eastern ABFT are known from the Mediterranean, as well as several

${ }_{54}$ distinct nursery grounds of ABFT in the Mediterranean, the eastern Atlantic (e.g. Gulf 
of Lions, Atlantic waters off Morocco and the Bay of Biscay) and western Atlantic, that could lead to, and indicate, a differentiation into subpopulations. Recent electronic tagging and genetic studies support the meta-population hypothesis, indicating that ABFT of eastern Atlantic origin are composed of several transient ("migratory") and resident ("sedentary") subpopulations with overlapping distributions (Riccioni et al., 2013; Fromentin and Lopuszanski, 2013; Cermeño et al., 2015).

The assessment of population structure and dynamics of highly migratory species such as ABFT are ultimately linked to our understanding of their behaviour and habitat use. Such knowledge thus represents key information for fisheries and stock management, i.e. for survey programs that seek to assess ABFT abundance (Fromentin et al., 2014a; Bauer et al., 2015a). In fact, ABFT can rapidly change their vertical and horizontal behaviour from resident to highly migratory states, from periods of surface orientation to repeated or long lasting dives (Brill and Lutcavage, 2001; Walli et al., 2009). In order to better understand the habitat use of ABFT, systematic patterns in ABFT behaviour and their driving forces need to be identified. Specific diving patterns have been described for ABFT spawning behaviour, as well as the oceanographic condition under which this occurs (e.g. a specific temperature and chlorophyll range, and the presence of mesoscale features such as eddies and fronts; Alemany et al. 2010; Aranda et al. 2013). Feeding grounds also appear to possess distinct oceanographic signatures. Accordingly, ABFT seem to aggregate in areas of high primary productivity (Walli et al., 2009) and mesoscale activity (fronts; Royer et al., 2004; Schick et al., 2004). In this context, Fromentin and Lopuszanski (2013) showed that ABFT in the northwestern Mediterranean displayed little year-to-year variations in their migratory behavior and further concentrated in a small area of the central northwestern Mediterranean, where they may stay for several months, probably for feeding. The attractiveness of this area as persistent feeding ground thereby results from local enrichment due to permanent mesoscale oceanographic features related to the North Mediterranean Current and the North Balearic front. The knowledge of such oceanographic preferences provides the opportunity to identify and predict foraging and spawning grounds through modelling approaches or electronic tagging experiments (Royer et al., 2005a; Teo et al., 2007; Druon et al., 2012; Lutcavage et al., 2013; Cermeño et al., 2015). Oceanographic conditions can therefore help us to explain variations in the quality, persistence and connectivity of important feeding grounds that likely affect the local dispersal and large scale distribution of this species, i.e. transatlantic exchange rates (Sibert et al., 2006; Walli et al., 2009; Fromentin et al., 2014b). Knowledge of habitat use, i.e. area and surface presence, is further crucial for the selection of study sites and the temporal window of aerial survey programs that seek to assess ABFT abundance, 
such as in the Gulf of Lions (Bauer et al., 2015a,c). In addition, information on surface presence is also required to assess the fraction of visible fish during such programs and this way to correct obtained abundance estimates.

In this study, we investigate the specific vertical behavioural patterns of apparently resident ABFT in the western Mediterranean Sea in relation to environmental conditions based on 8 years of electronic tagging data and different additional oceanographic datasets. We further examine the oceanographic characteristics of an area regularly utilized by ABFT, to the South of the Gulf of Lions, hereinafter termed "high-use" area, that was previously identified by Fromentin and Lopuszanski (2013).

\section{Material and Methods}

\subsection{Data sources}

\subsubsection{Tagging data}

The tagging data applied in the subsequent analyses was obtained from 36 pop-up archival tags (PAT; 31 MK10 tags and 5 miniPAT's from Wildlife Computers, Redmond, USA), which were all deployed on mature ABFT (124-255 cm fork length), caught using rod and reel on the shelf area off Marseille, France between July and November in 2007-2014 (Fig. 1; Tab. 1; Fromentin and Lopuszanski, 2013). These fish are mostly young adults that are supposed to migrate to majour Mediterranean spawning sites (i.e. the Balearic Islands, Sicily area and Gulf of Syrta) from late May to early July (Fromentin and Powers, 2005; Rooker et al., 2007). Most of our tags were deployed by Fromentin and Lopuszanski (2013) for the analysis of (seasonal) horizontal migration patterns, except for 9 omitted MK10 tags with corrupted data, transmission errors or/and short-term post-tagging mortality. Programmed deployment durations until pop-up ranged therefore between 240 and 365 days (Tab. 1). Pop-up archival tags generally record the ambient pressure, light levels and water temperature, experienced by the tagged animal, at fixed intervals (10 sec for MK10 tag, $5 \mathrm{sec}$ for the miniPATs). This information is then used to produce different data products, of which some are transmitted to the ARGOS satellite system after the tags release (pop-up), depending on the tag type and the user-defined settings of the tag. Alternatively, if the tag is physically recovered, the entire recorded data series is accessible. Transmitted data products of our tags included light levels and sea surface temperature (SST) measures, as well as different summary products of temperature and depth data at a predefined temporal resolution (12 or $24 \mathrm{~h}$ ). MiniPATs can also transmit time series data and were therefore deployed since 2013 to better study the vertical 
behaviour of tunas. Our miniPATs were programmed to transmit depth time series data at a temporal resolution of $10 \mathrm{~min}$, resulting in a maximum of 144 records per day. Of all the tags deployed, only one MK10 tag (\#92113) got returned, after being washed up onshore at Martigues (France). This recovery allowed us to access and analyze the entire recorded data sets of the different parameters over a deployment period of 162 days (August 2010-February 2011), including complete temperature and depth time series data. Given the comparable size of this fish at the time of tagging (160 cm vs $124-255$ $\mathrm{cm}$; Tab. 1) and similar horizontal behaviour (illustrated in the supplementary material), this data was considered to representative for the tagged population in the subsequent analyses.



Figure 1 Tagging location off Marseille, France (green dot) and transect lines of aerial surveys (blue) conducted in the study area. For more information on the aerial surveys see Bauer et al. (2015a) and Bauer et al. (2015c). The dashed lines represent the 200 and $2000 \mathrm{~m}$ isobaths, indicating the continental shelf break of the Gulf of Lions. Maps were drawn using the "plotmap"-function of the R-package "oceanmap" (Bauer, 2016). 
Table 1 Detailed information on the 36 pop-up archival tags deployed between 2007 and 2014 on the shelf area off Marseille, France.

\begin{tabular}{|c|c|c|c|c|c|c|c|c|c|c|c|}
\hline \multicolumn{2}{|c|}{ Tag } & \multirow{2}{*}{$\begin{array}{r}\text { Fish size } \\
(\mathrm{cm})\end{array}$} & \multicolumn{3}{|c|}{ Release } & \multicolumn{3}{|c|}{ Recapture } & \multicolumn{2}{|c|}{ Deployment duration (days) } & \multirow{2}{*}{$\begin{array}{r}\text { Total distance } \\
(\mathrm{km})\end{array}$} \\
\hline ID & Model & & Date & Longitude $\left({ }^{\circ} \mathrm{E}\right)$ & Latitude $\left({ }^{\circ} \mathrm{N}\right)$ & Date & Longitude $\left({ }^{\circ} \mathrm{E}\right)$ & Latitude $\left({ }^{\circ} \mathrm{N}\right)$ & Programmed & Final & \\
\hline$\# 68405$ & MK10 & 127 & $2007-09-21$ & 4.73 & 43.23 & $2007-12-16$ & 4.03 & 41.20 & 240 & 86 & 1026.0 \\
\hline \#68409 & MK10 & 127 & $2007-09-22$ & 4.73 & 43.23 & 2008-02-07 & 12.27 & 35.71 & 365 & 138 & 1507.5 \\
\hline \#68402 & MK10 & 124 & $2007-09-24$ & 4.73 & 43.23 & 2007-10-07 & 9.18 & 38.26 & 240 & 13 & 826.0 \\
\hline \#68404 & MK10 & 128 & $2007-09-24$ & 4.73 & 43.25 & 2007-11-17 & 2.48 & 40.89 & 240 & 54 & 1014.9 \\
\hline \#68406 & MK10 & 128 & $2007-09-24$ & 4.73 & 43.23 & 2008-01-22 & 7.19 & 43.59 & 365 & 120 & 955.6 \\
\hline \#68403 & MK10 & 235 & 2007-10-03 & 4.97 & 43.28 & 2007-11-11 & 4.85 & 38.46 & 240 & 39 & 881.6 \\
\hline \#37332 & MK10 & 128 & $2007-11-03$ & 4.93 & 43.23 & 2007-11-08 & 4.88 & 39.17 & 270 & 5 & 727.8 \\
\hline \#87641 & MK10 & 228 & $2008-08-21$ & 5.40 & 43.05 & $2008-10-30$ & 6.90 & 38.69 & 365 & 70 & 1068.6 \\
\hline \#87644 & MK10 & 188 & 2008-08-21 & 5.40 & 43.05 & 2008-09-03 & 3.52 & 41.07 & 365 & 13 & 466.7 \\
\hline \#87642 & MK10 & 210 & $2008-10-26$ & 4.91 & 43.26 & 2009-06-10 & 18.32 & 31.89 & 365 & 227 & 2876.2 \\
\hline \#87643 & MK10 & 143 & $2008-10-26$ & 4.91 & 43.26 & 2008-12-19 & 3.95 & 42.03 & 365 & 54 & 670.4 \\
\hline \#80082 & MK10 & 144 & 2008-11-08 & 4.92 & 43.23 & 2009-04-17 & 14.48 & 40.09 & 365 & 160 & 2129.8 \\
\hline \#80084 & MK10 & 198 & 2009-08-16 & 4.82 & 43.27 & 2010-01-05 & 4.95 & 41.32 & 365 & 142 & 1765.0 \\
\hline \#92108 & MK10 & 180 & $2009-08-20$ & 4.80 & 43.27 & 2010-06-16 & 7.08 & 38.78 & 365 & 300 & 2315.0 \\
\hline \#92107 & MK10 & 192 & 2009-08-21 & 4.80 & 43.27 & 2009-12-07 & 5.98 & 37.99 & 365 & 108 & 1133.4 \\
\hline \#92110 & MK10 & 180 & $2009-08-28$ & 4.98 & 43.27 & 2010-01-02 & 11.03 & 37.42 & 365 & 127 & 1559.4 \\
\hline \#92115 & MK10 & 160 & 2009-09-11 & 4.82 & 43.27 & 2010-02-06 & 8.00 & 38.01 & 365 & 148 & 1627.9 \\
\hline \#92112 & MK10 & 255 & $2010-08-10$ & 4.92 & 43.27 & $2010-08-26$ & 3.97 & 41.85 & 240 & 16 & 718.6 \\
\hline \#92113 & MK10 & 160 & $2010-08-28$ & 4.82 & 43.27 & 2011-02-03 & 5.22 & 43.15 & 240 & 159 & 2316.9 \\
\hline \#92114 & MK10 & 160 & 2010-09-01 & 4.89 & 43.27 & $2011-02-23$ & 4.70 & 41.02 & 240 & 175 & 1790.9 \\
\hline \#34261 & MK10 & 156 & 2010-09-24 & 4.87 & 43.27 & 2011-01-12 & 13.12 & 40.89 & 365 & 110 & 1520.5 \\
\hline \#92116 & MK10 & 160 & 2010-09-24 & 4.87 & 43.27 & $2011-05-17$ & 4.38 & 42.48 & 240 & 235 & 2055.7 \\
\hline \#34273 & MK10 & 165 & 2011-08-06 & 4.78 & 43.27 & 2011-11-07 & 7.29 & 43.60 & 365 & 93 & 3463.2 \\
\hline \#61954 & MK10 & 165 & 2011-08-24 & 4.90 & 43.27 & 2012-01-18 & 13.08 & 41.25 & 365 & 147 & 3702.1 \\
\hline \#61964 & MK10 & 185 & 2011-09-16 & 4.93 & 43.28 & 2012-09-11 & 4.99 & 43.40 & 365 & 361 & 10728.6 \\
\hline \#61966 & MK10 & 207 & 2011-09-17 & 4.93 & 43.30 & $2011-11-24$ & 4.79 & 41.91 & 365 & 68 & 2181.7 \\
\hline \#62017 & MK10 & 177 & 2012-08-02 & 4.92 & 43.28 & 2012-08-27 & 5.06 & 42.33 & 365 & 25 & 1226.0 \\
\hline \#73421 & MK10 & 205 & 2012-09-09 & 4.92 & 43.27 & 2012-12-08 & 11.59 & 36.40 & 365 & 90 & 1340.8 \\
\hline \#61969 & MK10 & 168 & 2012-10-14 & 4.92 & 43.27 & 2013-06-04 & 4.87 & 44.07 & 365 & 233 & 5265.2 \\
\hline \#73423 & MK10 & 183 & 2013-08-04 & 4.92 & 43.30 & 2014-03-31 & 3.50 & 39.70 & 365 & 239 & 4891.1 \\
\hline \#112623 & miniPAT & 200 & 2013-08-12 & 4.93 & 43.30 & $2014-02-21$ & 14.31 & 35.22 & 365 & 193 & 4607.8 \\
\hline \#112625 & miniPAT & 187 & 2013-08-15 & 4.91 & 43.28 & 2014-08-10 & 4.70 & 42.80 & 365 & 360 & 7404.3 \\
\hline \#112632 & $\operatorname{miniPAT}$ & 227 & 2013-08-19 & 4.91 & 43.28 & 2013-09-07 & 5.20 & 41.52 & 365 & 19 & 809.3 \\
\hline \#112627 & $\operatorname{miniPAT}$ & 180 & 2013-09-05 & 4.89 & 43.28 & 2013-10-29 & 4.57 & 42.72 & 365 & 54 & 1542.7 \\
\hline \#112626 & $\operatorname{miniPAT}$ & 179 & 2013-09-07 & 4.91 & 43.28 & 2014-09-02 & 5.00 & 43.20 & 365 & 360 & 9361.9 \\
\hline
\end{tabular}

Daily geolocations of the tags were estimated by CLS (Collecte Localisation Satellite, France) based on a state-space model which incorporates the light level and SST data of the tags and further considers bathymetric constraints (Royer et al., 2005b). For our analyses we used geolocation and sea surface temperature (SST) estimates of the tags, as well as depth time series and summary data. The latter refers to Time-at-Depth histogram data (TAD) that gives the percentage of time spent at up to 14 depth intervals, during a fixed time span. The setup settings of TAD time and depth intervals differed among tags (Tab. S1). As such TAD data were standardized following their reception by selecting a daily $(24 \mathrm{~h})$ sampling interval and 10 shared depth-bins $(0,10,20,50,100$, $200,300,400,600$ and $>600 \mathrm{~m}$ ). The underlying algorithm is now implemented in the function "merge_histos" of the R-package "RchivalTag" (Bauer, 2017). In general, daily TAD data sets were rather incomplete, due to transmission problems through the ARGOS system in the area of Mediterranean Sea (Fig. S1). As miniPAT tags also transmitted depth time series data, we tested whether complete daily datasets of this data (144 records per day) could be used to fill gaps in the daily TAD data. The results, based on 29 days of data, revealed a high correlation between transmitted and reconstructed TAD profiles of miniPATs $\left(R^{2}=0.76\right.$ for all depth bins and $R^{2}=0.94$ for the $0-10 \mathrm{~m}$ 
depth bin). We therefore considered TAD profiles reconstructed from transmitted depth time series data to be sufficiently representative and used them to complete missing daily TAD profiles for the miniPATs. In total 1643 daily TAD profiles of a theoretical number of 4773 deployment days could be analysed, corresponding to a data coverage of $31.1 \%$ (Fig. S1). By contrast, SST and geolocation estimates provided complete daily time series as they were estimated through other approaches that rely on other transmitted datasets (see above).

\subsubsection{Oceanographic data}

In order to investigate potential environmental influences on the vertical and horizontal behaviour of ABFT in the NW Mediterranean, we collected oceanographic data from different data sources. Daily SST and chlorophyll a (chla) satellite images, covering the entire western Mediterranean Sea and entire tag deployment period (2007-2014), with a spatial resolution of $4 \mathrm{~km}$ from the Moderate Resolution Imaging Spectroradiometer (MODIS-Aqua) was obtained from the NASA ocean colour web server (http://oceancolor.gsfc.nasa.gov/). These data sets were averaged over +/3 days, in order to maximise spatial data coverage, which can otherwise be impaired by clouds. Based on the obtained averaged images chla and SST front locations were calculated by applying the front detection algorithm presented by Nieto et al. (2012). As a criteria to select only strong thermal and chla fronts, that are probably more meaningful in terms of biological productivity, we chose only fronts whose average gradients were larger than $0.01 \mathrm{mg}$ chla $\mathrm{m}^{-3} \mathrm{~km}^{-1}$ for chla fronts and $0.042{ }^{\circ} \mathrm{C} \mathrm{km}^{-1}$ for SST fronts, respectively. These gradient thresholds were chosen based on the respective median gradients from multi-annual chla and SST fronts in the world's oceans (Roa-Pascuali et al., 2015).

In addition, we assessed the thermal stratification of the waters surrounding the estimated locations of tagged fish. PAT temperature data, such as PAT-style Depth-Temperature Profiles (PDT), can be used to perform this task, but was also only transmitted in fragments and not completely overlapping with the TAD data (Bauer et al., 2015b). To achieve higher data coverage, we applied 3-D temperature data from the western Mediterranean, obtained from the coastal ocean model SYMPHONIE (Marsaleix et al., 2008). This high resolution model has been shown to perform well in reproducing the circulation of the northwestern Mediterranean, including complex mesoscale features in the Gulf of Lions (e.g. eddies; Hu et al., 2009). Data from two different configurations of this model were available for this analysis. The first configuration covered the study years 2000-2011 and the entire extent of the western Mediterranean with 43 vertical layers and 
a slightly irregular grid at a horizontal resolution of around $10 \mathrm{~km}$ in the Mediterranean basin and $7 \mathrm{~km}$ in the area of the strait of Gibraltar. The second configuration covered the period from June 2011 onwards and most of the western Mediterranean, except it's southeastern and southwestern edges, with 40 vertical layers and an irregular grid spacing of $0.9-1.4 \mathrm{~km}$ (Fig. S2). To identify the depth and gradient of the thermocline, we applied the thermocline detection algorithm of Fiedler (2010) that is now implemented in the function "get_thermalstrat" of the R-package "RchivalTag" (Bauer et al., 2015b; Bauer, 2017). In order to validate stratification and thermocline indices, we compared obtained estimates between models and with results from in-situ temperature profiles from the western Mediterranean, gathered from the World Ocean Database (www .nodc .noaa.gov). The results of this preliminary analysis showed that both SYMPHONIE configurations performed well in reproducing the thermocline, particularly its gradient, and that estimates between models were comparable (Tab. 2).

Table 2 Pearson's correlation coefficients of thermocline depth and gradient estimates between in-situ profiles and closest grid points of the two SYMPHONIE configurations, as well as between estimates for tag geolocations of both SYMPHONIE models (see subsection 2.4.2).

\begin{tabular}{lccc}
\hline & \multicolumn{2}{c}{ CTD vs. SYMPHONIE } & Between \\
& $2000-2011$ & since June 2011 & SYMPHONIE models \\
\hline $\mathrm{n}$ & 736 & 123 & 173 \\
thermocline depth & $0.42^{*}$ & $0.65^{*}$ & $0.83^{*}$ \\
thermocline gradient & $0.93^{*}$ & $0.94^{*}$ & $0.94^{*}$ \\
\hline${ }^{*} p \leq 0.01$ & & &
\end{tabular}

\subsection{Vertical behaviour}

\subsubsection{Clustering daily TAD profiles}

In order to identify different daily vertical behaviour types of ABFT in the NW Mediterranean Sea, daily TAD profiles were first transferred to cumulative frequency distributions (CFD) that served then as input data for the clustering. To do so, we used a monotone cubic spline with Hyman filtering regression, interpolating the relative frequencies of the TAD profiles over a depth range of $0-900 \mathrm{~m}$ with a resolution of $10 \mathrm{~m}$. Furthermore, we chose an artificial depth limit of $900 \mathrm{~m}$ for the $>600 \mathrm{~m}$-depth interval to avoid overemphasising the tail section of the depth distribution in the later clustering, although ABFT do infrequently reach deeper waters (Walli et al., 2009). The interpolated CFDs 
allowed thereby a quasi-continuous data treatment during the clustering process, despite the varying depth-bin widths of the TAD data (see above).

Based on the thus transformed daily vertical profiles (TAD $\rightarrow$ CFD), we computed an Euclidean distance matrix, using the "dist"-function of the "stats"-R-package. This distance matrix served as input for a hierarchical clustering approach, for which we applied the "complete linkage"-method that seeks the similarity (shortest distance) between clusters. The latter calculation was thereby conducted with the "hclust"-function of the same R-package. To select the most meaningful clusters (i.e. with the largest distance to each other), we decided to cut the resultant dendrogram at a variable and not at a constant height, using the "cutreeDynamic"-function of the R-package "dynamicTreeCut" (Langfelder et al., 2008). To cross-validate the cluster selection, we examined the corresponding average TAD profiles of different clusters as well as differences in the monthly frequencies per cluster. In addition, we used the depth time series data of the recovered MK10 tag (\#92113) to better understand the underlying dive patterns of the clustered vertical profiles.

\subsubsection{Diel patterns}

Depth time series data obtained from the recovered MK10 tag (\#92113) and the 5 miniPAT tags was used to investigate diel patterns in the vertical behaviour. Two parameters were investigated, i) the depth at which the fish were located and ii) the percentage of time spent in the surface layer $(0-10 \mathrm{~m})$. The complete time series of the MK10 tag allowed us to investigate hourly patterns. By contrast, only day-night comparisons were conducted for the miniPATs, due to their low proportion of successfully transmitted data. As such, we only considered data sets for which at least $50 \%$ of possible records were available per night or day periods. To split this data into day- and nighttime, we estimated the time of sunrise and sunset as well as the astronomical dusk and dawn using the functions "sunriset" and "crepuscule" of the R-package "maptools" (Bivand and Lewin-Koh, 2015). These functions are based on equations from Meeus (1991) and required date and geolocation estimates of the tags as input, accounting for seasonal changes in the length of day- and nighttimes.

\subsection{Horizontal behaviour}

We examined seasonal changes in the dispersal patterns of ABFT, based on kernel densities of tag geolocation estimates. Seasons were defined as followed: winter: December-February, spring: March-May, summer: June-August, autumn: September-November. Kernel densities were calculated using the "kde2d"-function from the 
R-package "MASS" with a search radius of 1 degree (Venables and Ripley, 2002).

\subsection{Migratory behaviour in relation to environmental conditions}

\subsubsection{Oceanographic characteristics of the high-use area}

In a preliminary study based on the horizontal tracks obtained from the ABFT tags deployed until 2011, Fromentin and Lopuszanski (2013) could identify an area of high ABFT residency in the NW Mediterranean. This "high-use" area is located between $4-6^{\circ} \mathrm{E}$ and $43-41^{\circ} \mathrm{N}$, and included $50 \%$ of the respective daily geolocations. Fromentin and Lopuszanski (2013) hypothesized that the preference of ABFT for this area could result "from local enrichment due to permanent mesoscale oceanographic features related to the North Mediterranean Current and the North Balearic front." In order to test this hypothesis, it is necessary to identify the specific oceanographic characteristics of this area that distinguish it from other regions in the western Mediterranean. To do so, we compared daily SST and chla levels as well as the frequencies (coverage) of strong oceanic fronts in this area with the respective values from 100 random areas of the same size in the western Mediterranean. This analysis was based on all pre-treated satellite images from 2007 to 2014 (see above).

\subsubsection{Modelling surfacing behaviour}

Surface orientation represents an important component of ABFT vertical behaviour related to horizontal migration and feeding behaviour (Scott and Flittner, 1972; Newlands and Porcelli, 2008). In fact, spotter planes have been used by many fisheries to locate bluefin tuna schools (Farrugio et al., 1977; Lutcavage and Kraus, 1997; Basson and Farley, 2014). This behaviour also provides a promising opportunity to develop fishery independent indicators of ABFT abundance based on aerial surveys (Eveson et al., 2012; Bauer et al., 2015a). However, it is important to identify factors that can affect the surface-availability of ABFT. Generalized Additive Models (GAM; Wood, 2006) have been used to model habitat preferences of diverse tuna species, including ABFT. Here, we applied a GAM to model the daily surface-availability of ABFT (daily percentage of time spent in the surface layer, $0-10 \mathrm{~m}$ ), based on the TAD profiles and the environmental data presented earlier. Geolocation estimates (longitude/latitude), fish size and environmental variables (SST, thermocline depth and gradient) were introduced as smoothing terms (thin plate regression splines). To account for the uncertainty in geolocations on thermocline gradient and depth estimates, we applied the average estimates of all grid points in a radius of 0.5 degrees around tag geolocations. By contrast, SST estimates were taken 
from the received PAT data. To assess temporal effects, we applied "month", "season" and "year" as factorial variables. Modelling was conducted using the "gam"-function of the R-package "mgcv" (Wood, 2006). Models were run separately on data from the recovered tag (\#92113) and on the merged data sets from tags with at least 60 days of TAD data (multi-tag models), representing 10 tags in total (\#68404, \#87641, \#87643, \#92107, \#92113, \#92114, \#34273, \#61966, \#112623, \#112626; Tab. 1; Fig. S1). Model selection was based on the Akaike's information criterion (AIC) and further evaluated with residual analysis.

\section{Results}

The deployment of 36 archival tags provided 1643 daily summaries (TAD data) of ABFT vertical behaviour from 4773 days of tag deployment. Moreover, one of these tags was recovered, providing high resolution vertical data (every $10 \mathrm{~s}$ ) over a deployment period of 162 days (August 2010-February 2011). The TAD data indicated that tagged ABFT exhibited a generally high surface presence $(0-10 \mathrm{~m})$ (Fig. 2), which included more than a third of the daily ( $24 \mathrm{~h}$ ) depth records. No similar maximum was observed for deeper depths due mainly to the unequal width of depth bins. However, the clustering of these profiles allowed us to distinguish four different behavioural patterns, revealing the existence of a seasonal succession in the vertical behaviour of ABFT (Figs. 2 and 3). Accordingly, surface orientation of ABFT, predominant during summer, became less frequent during the winter months (December-March), when ABFTs occupied more often larger depths. Kernel densities of tag geolocations showed a similar seasonality in the horizontal dispersal. The seasonality in both migratory behaviour types indicated links to environmental conditions. An examination of such effects using GAMs, showed links between the daily time spent at the water surface and the thermocline gradient as well as regional dependencies. Environmental datasets (chla and ocean fronts) highlighted the enhanced productivity of the high-use area compared to the rest of the western Mediterranean.

\subsection{Vertical behaviour}

\subsubsection{Clustering daily TAD profiles}

After carefully examining the dendrogram of the vertical profiles as well as differences in the average TAD profiles of potential clusters and their monthly frequencies (Fig. 2, we decided to distinguish four clusters of vertical behaviour. Average TAD profiles of all 
clusters showed a maximum in the $0-10 \mathrm{~m}$ depth bin, indicating that surfacing represents an important component in ABFT behaviour. The presence in this depth interval is particularly pronounced in cluster 1 , the most abundant cluster, here accounting for an average of $\sim 50 \%$ of all daily $(24 \mathrm{~h}$ ) depth records vs. $\sim 25 \%$ in the other clusters. This cluster is also characterized by a sharp decrease in the time spent in lower depths. Considering the unequal width of the depth intervals (bins), a continuous decrease of ABFT presence with increasing depth is also evident in the other clusters, although less pronounced. Accordingly, the average histogram of cluster 2 shows a more uniform presence in the first 3 depth bins. By contrast, average histograms of cluster 3 and 4 are U-shaped, with elevated presence levels of ABFT at the surface and between 50 and $200 \mathrm{~m}$. In both of these clusters, ABFT were located below $50 \mathrm{~m}$ for more than $50 \%$ of the day $(24 \mathrm{~h})$. However, cluster 4 differs from the other three clusters in the relatively high proportion of presence throughout the lower depth bins $(>200 \mathrm{~m})$. The inspection of depth time series data from the recovered MK10 tag revealed that this pattern is the result of very deep and long lasting dives. Despite their rather long duration, some of these dives had the specific signature of spike dives, being periodically conducted at twilight with rapid ascents and descents at sunrise and sunset, respectively (Fig. 4). However, this pattern was not always accurately identified by the clustering process, due to the co-occurrence of different diving patterns per day. Due to the distinctness and behavioural relevance of this pattern, we decided to assign any TAD profile with at least $3 \mathrm{~h}$ per day spent below $200 \mathrm{~m}$ to this cluster, regardless of the remaining behaviour patterns. This operation had no significant effects on the subsequent findings related to the other clusters.

We termed clusters 1 and 2 as behaviour types of marked surface and subsurface orientation, and clusters 3 and 4 as types of moderate and deep diving behaviour, respectively. An analysis of the succession of these clusters per tag revealed that periods of constant, as well as alternating, vertical behaviour frequently occurred (Fig. 3). However, on a monthly basis, opposing seasonal trends in the frequencies of clusters 1 and 2 were evident (correlation of monthly frequencies per year $R^{2}=-0.57$; correlation of average monthly frequencies: $R^{2}=-0.78$; Fig. 2). Cluster 1 (surface orientation) increased in frequency during early spring (April) and appeared to continue occurring regularly during summer (June-August), although data was scarce. Subsequent monthly frequencies of cluster 1 decreased until the end of winter (March). By contrast, cluster 2, indicating subsurface orientation, was very infrequent during summer, but occurred more regularly during autumn-winter. This observation further confirms our cluster selection, given the opposing trend between these neighbouring clusters. Cluster 3 (moderate diving 
behaviour) was most frequently observed during colder months. Cluster 4, indicating deep diving behaviour, was more common during the first half of the year than during the second (22.4\% relative frequency during Jan-June vs $7.6 \%$ during July-December). 



Figure 2 Average daily TAD profiles (left) of all data sets available (grey) and per TAD cluster (coloured) as well as the corresponding monthly frequencies per cluster during single deployment years (right). Estimated monthly frequencies per cluster and deployment year are based on at least 10 clustered daily TAD profiles per month. 
R. K. Bauer et al.: Bluefin tuna in the northwestern Mediterranean Sea

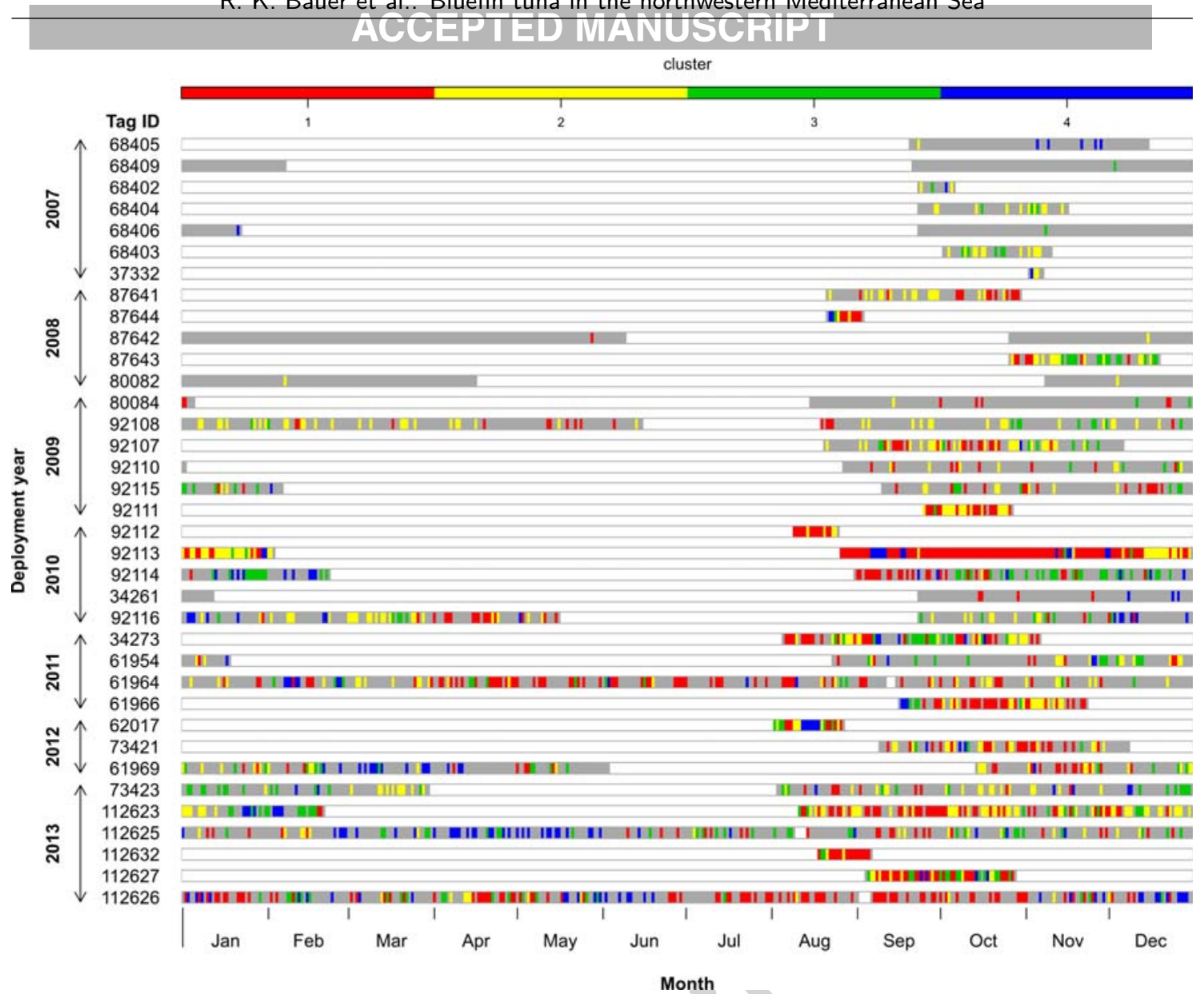

Figure 3 Clusters of daily TAD profiles throughout the deployment period (grey) of each tag. For average TAD profiles per cluster see Fig. 2. Note that tags were generally deployed during August to November, so that the period from January to August corresponds to the subsequent year after tagging. 


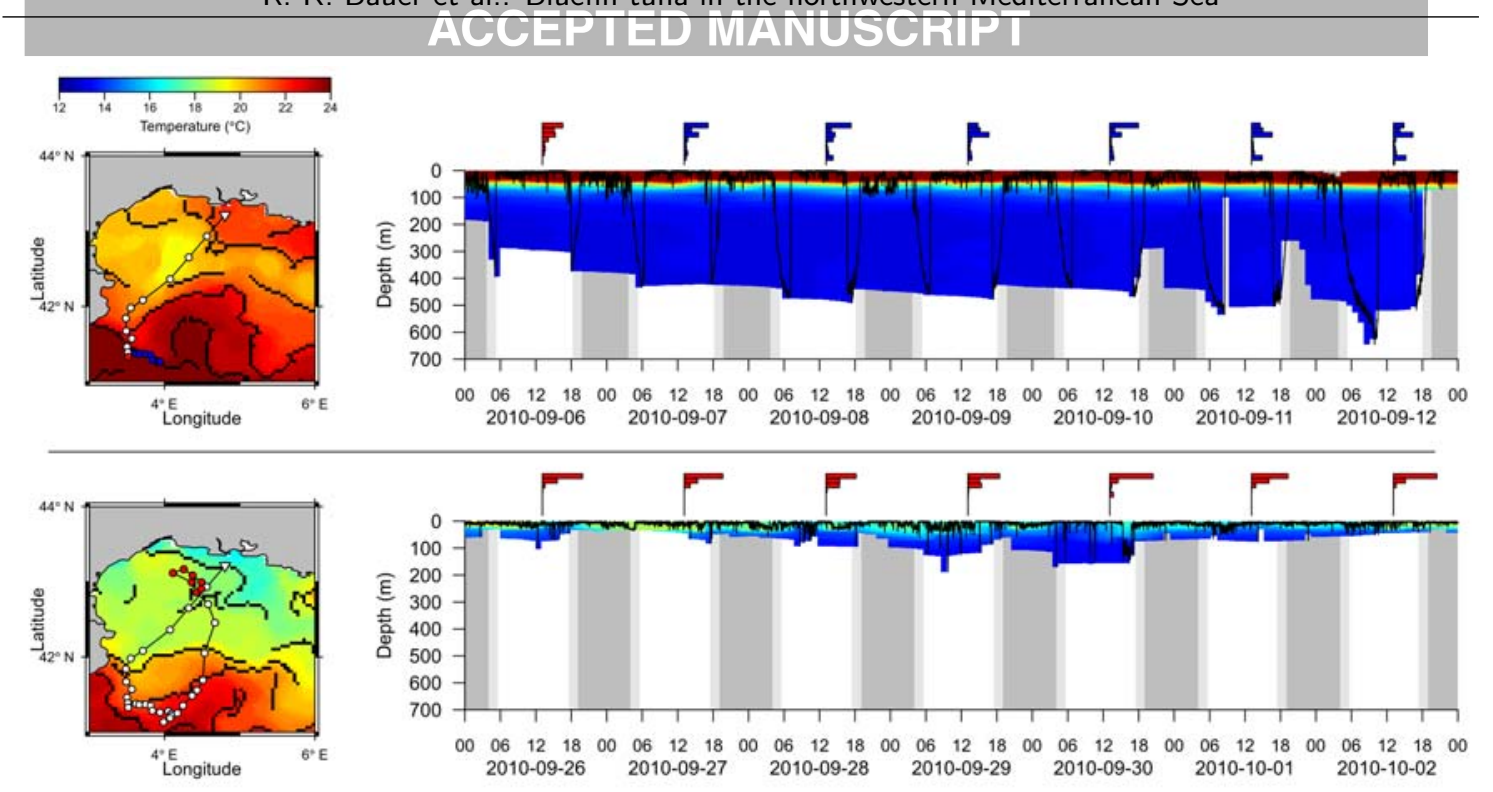

Figure 4 Left: Horizontal tracks of the MK10-tag \#92113 during two weeks of September 2010 (upper panel: 2010-09-06-2010-09-12; lower panel: 2010-09-26-2010-10-02) with SST and thermal front locations (black lines). Right: The corresponding depth time series data with daily TAD profiles and the water temperature fields experienced by the fish (interpolated). Daily geoloactions of each week and their corresponding TAD profiles are coloured according to their respective TAD-clusters. Earlier geolocations (since tag deployment) are indicated by white dots, the tagging position by a white inverted triangle. Night and twilight periods along the vertical tracks (right) are indicated in dark-grey and light-grey, respectively. For the entire vertical and horizontal tracks, please see Fig. S3. Maps and time series plots were drawn using the functions "plotmap" and "plot_TS" of the R-packages "oceanmap" and "RchivalTag", respectively (Bauer, 2016, 2017).

\subsubsection{Diel patterns}

Depth time series data revealed diel patterns in the vertical behaviour of ABFT in the western Mediterranean Sea (Fig. 5 \& 6). However, these patterns were not constant, but showed temporal variations. From August to September 2010, tag \#92113 was located close to the surface during daytime, but deeper during the night. This pattern was reversed during October and remained so until the beginning of February, when the tag released. Respective changes in the diel vertical behaviour regularly occurred at twilight, often marked by spike dives (Fig. 4). During the night this individual still frequented shallow waters until November, and then showed a general switch to deeper waters. Note that the latter can also be seen from the clustering analysis (Fig. 3), in particular, by the switch in dominance of cluster 1 (surface orientation) to cluster 2 (subsurface orientation) and cluster 3 (moderate diving behaviour). The data obtained from the five miniPATs, which were all deployed in 2013, indicated comparable temporal changes in the diel vertical behaviour (Fig. 7). Until November, these fish were frequenting shallower waters during the day than during the night. The few available records from December 
and January also suggest an inverted pattern during winter.
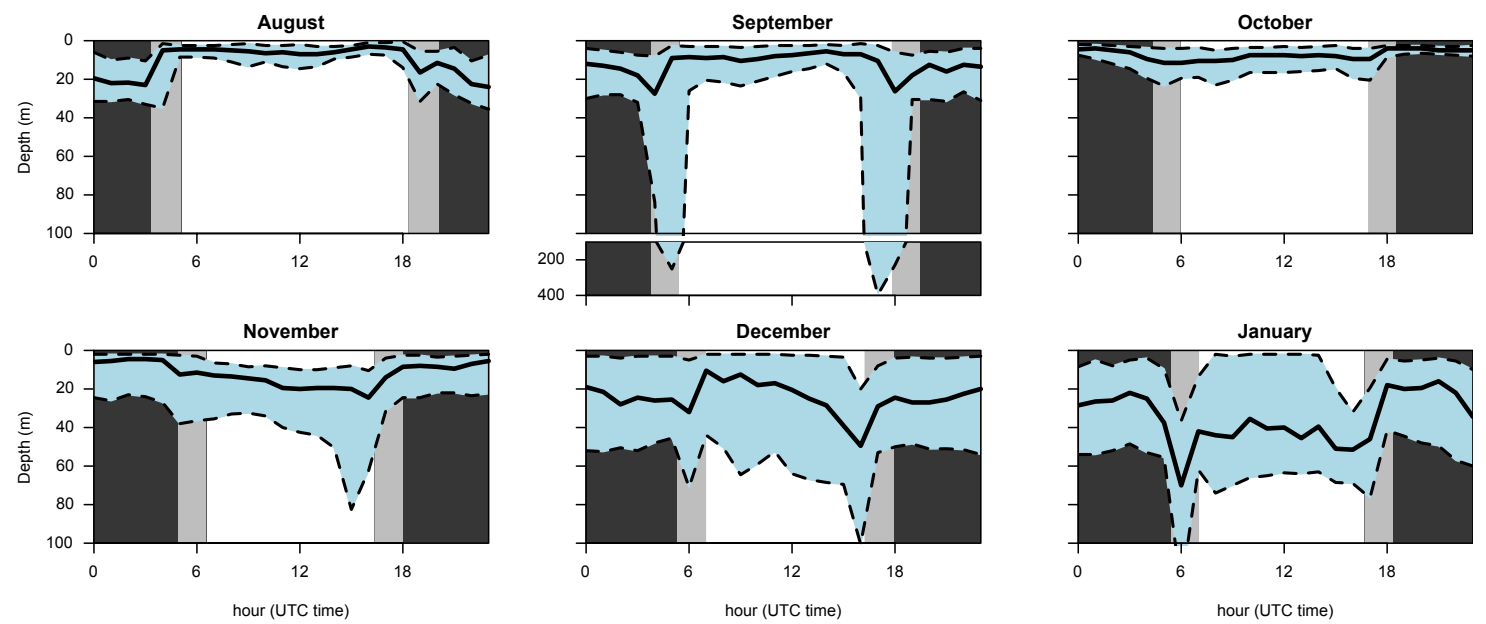

Figure 5 Median absolute depth (solid line) per hour and month as well as the corresponding first and the third quartiles (dashed lines), based on the $10 \mathrm{~s}$ depth time series data of the recovered MK10-tag \#92113. Average night and twilight periods per month are indicated in dark-grey and light-grey, respectively.
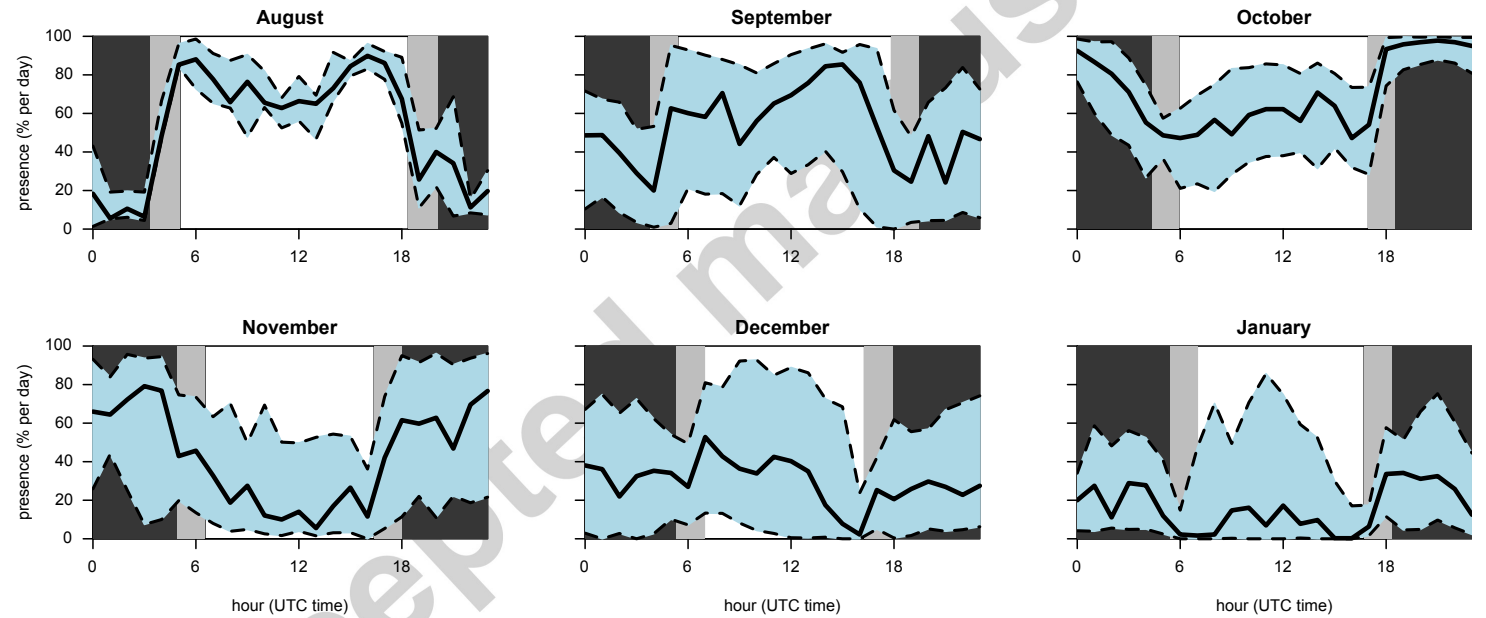

Figure 6 Median presence in the surface layer (0-10 m; solid line) per hour and month as well as the corresponding first and the third quartiles (dashed lines), based on the $10 \mathrm{~s}$ depth time series data of the recovered MK10-tag \#92113. Average night and twilight periods per month are indicated in dark-grey and light-grey, respectively. 

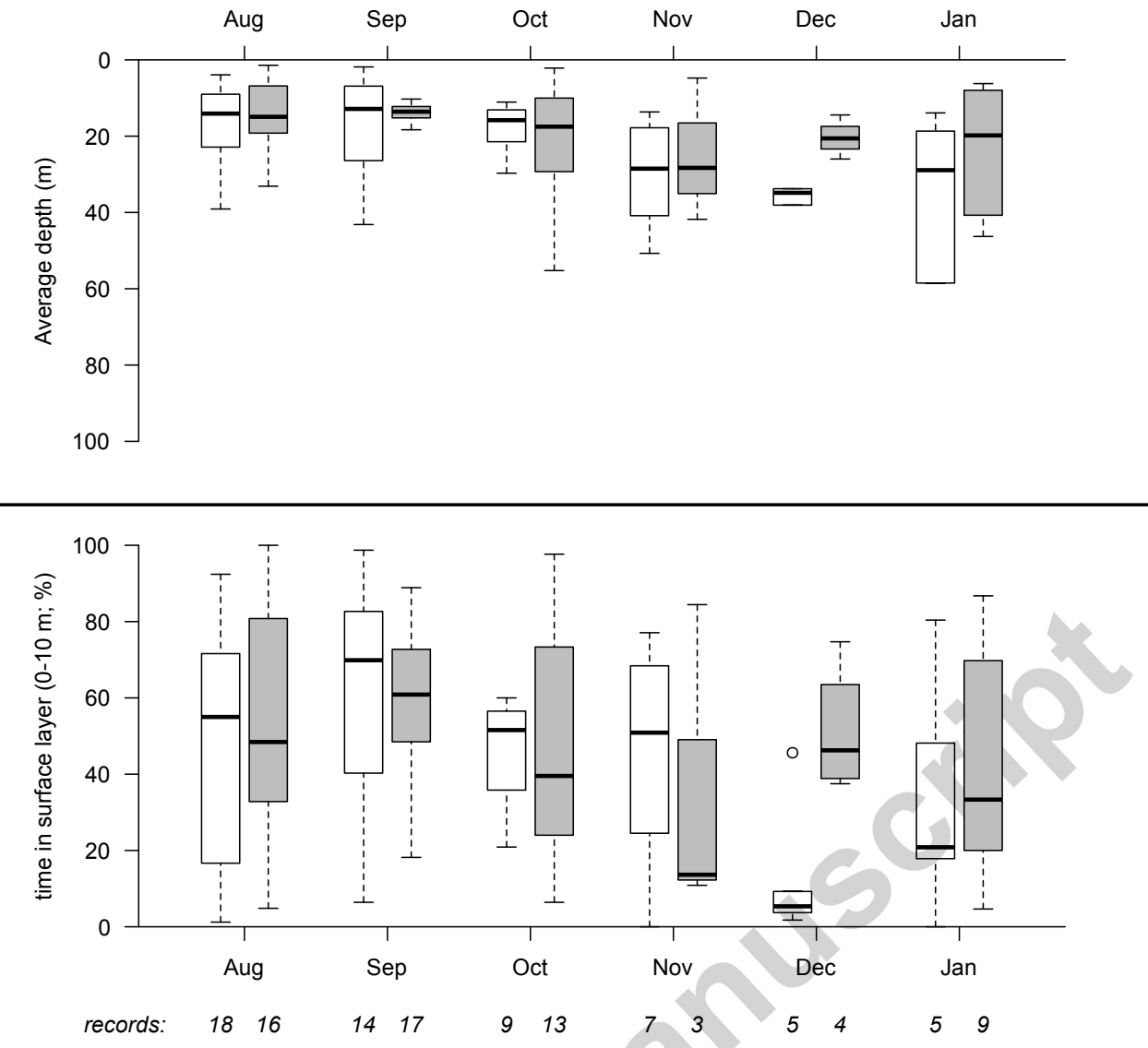

Figure 7 Average depth (upper panel) and time spent in the surface layer (0-10 m; lower panel) of miniPAT tags during night (grey) and daytime (white) per month. Boxplots are based only on daytime records with at least $66 \%$ data coverage, whose number is indicated in the lower panel.

\subsection{Horizontal behaviour}

Dispersal patterns of ABFT inferred from kernel densities of tag geolocations revealed seasonal changes relative to the location of the high-use area (Fig. 8). Accordingly, tagged ABFT frequented mainly near-coastal waters of the Gulf of Lions during summer (June-August). Strongest overlap with the high-use area to the Southeast of the Gulf of Lions was evident during autumn (September-November). By contrast, dispersal was higher during the winter (December-February) and spring (March-May) seasons. 


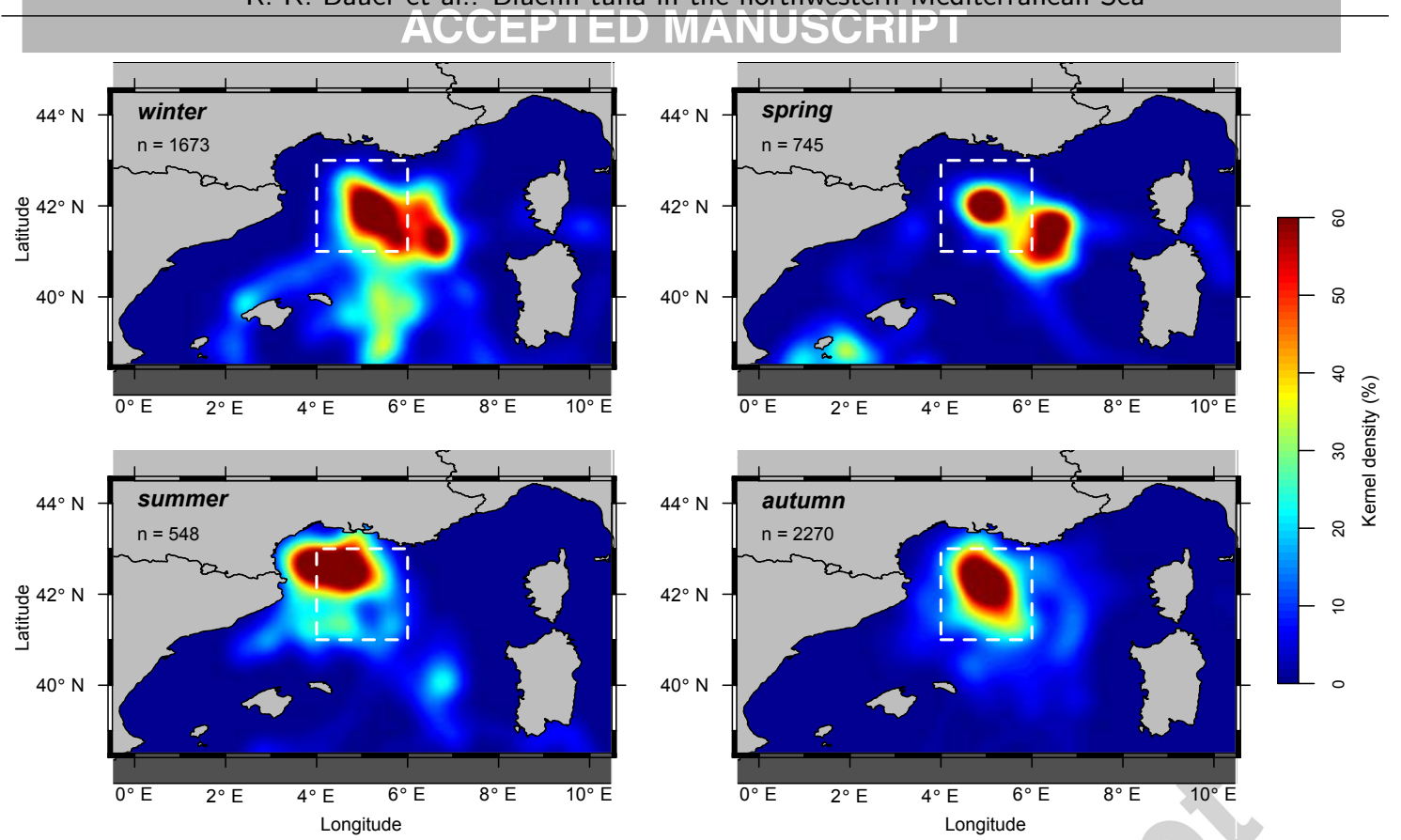

Figure 8 Seasonal kernel densities of ABFT geoposition estimates from 2007-2014, with the high-use area of ABFT (white dashed line), identified by Fromentin and Lopuszanski (2013). Seasons were defined as followed: winter: December-February, spring: March-May, summer: June-August, autumn: September-November.

\subsection{Migratory behaviour in relation to environmental conditions}

The high quality data (horizontal and vertical tracks) obtained from the recovered MK10 tag \#92113 gave us some important insights into ABFT behaviour, particularly in relation to thermal ocean fronts around the shelf area of the Gulf of Lions (Fig. 4). After tagging this individual left the Gulf of Lions area and moved southwest, where it encountered a strong thermal ocean front. For a several days, this fish closely followed the course of the front. During this time, it conducted periodic spike dives to depths of $>600 \mathrm{~m}$ lasting up to $4 \mathrm{~h}$. Afterwards, the fish moved back to the Gulf of Lions where it switched back to surface orientation $(0-10 \mathrm{~m})$. This behaviour remained the most pronounced during the subsequent weeks, while the fish continued to stay in the Gulf of Lions (Fig. S3). The fish's second departure from the Gulf of Lions, and subsequent southern movement, coincided with the breakdown of the thermal stratification in this area (Figs. 9 and 10 ), with less constant dive patterns but frequent visits to the high-use area. Vertical behaviour of this fish did not appear to be related to the position of the thermocline, but after the loss of thermal stratification this fish moved to deeper waters and showed more frequent changes in depth (Fig. 9). 


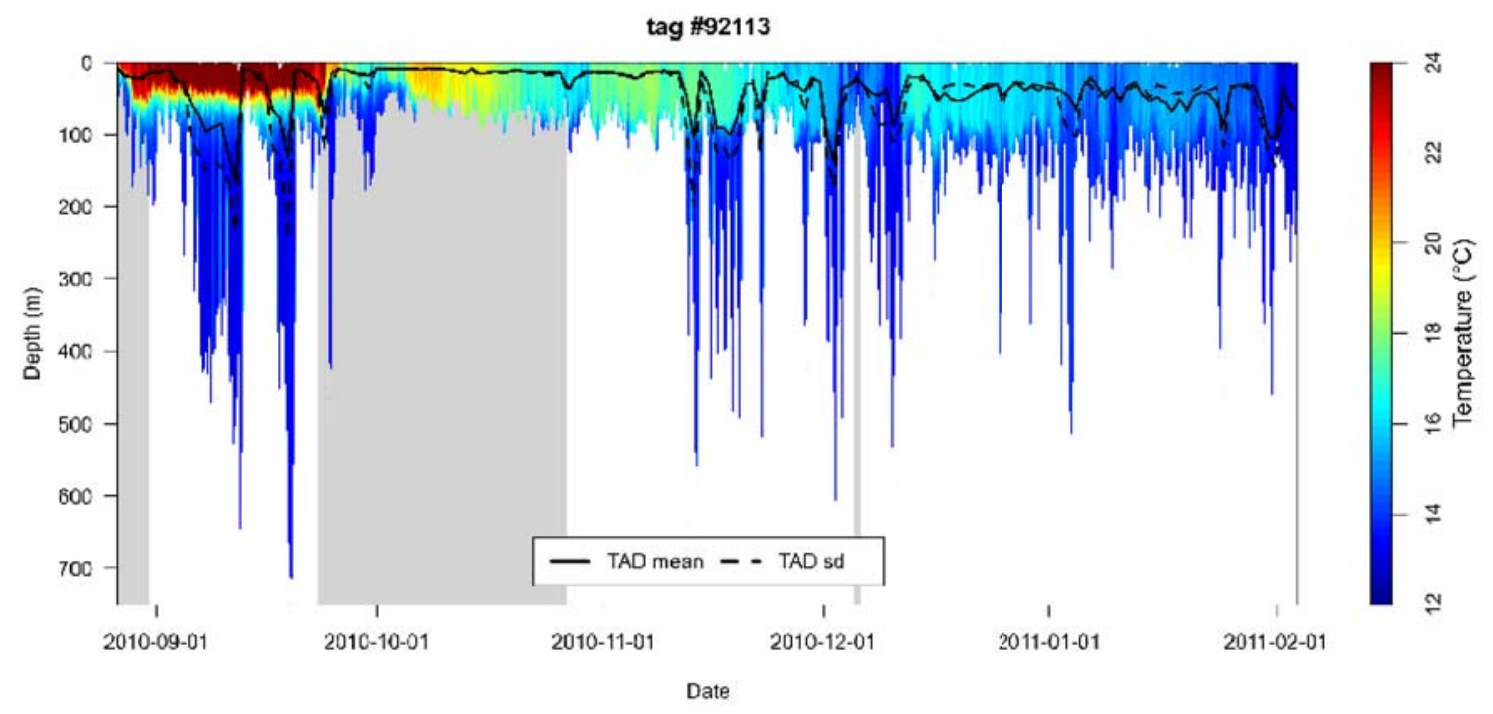

Figure 9 Average depth per day and its standard deviation of tag \#92113 on 6 h-interpolated temperature fields experienced by the tag throughout its deployment period. The grey-shaded area indicates periods of presence in the Gulf of Lions (Latitude $>42$ ).

\subsubsection{Oceanographic characteristics of the study zone and ABFT high-use area}

All evaluated oceanographic indicators (SST, chla, thermal- and chla-fronts, thermocline depth and gradient) exhibited seasonal patterns in the whole western Mediterranean Sea and in the ABFT high-use area (Fig. 10). SST, as well as the frequency of thermal fronts, generally decrease from August until February and increase again thereafter. By contrast, the thermocline builds up faster (during April) than it diminishes, although its gradient shows a similar seasonal pattern as SST. The chla concentration and the frequency of respective fronts showed an inverted, slightly displaced pattern, with highest values being reached during spring (March-April) and lowest during summer/early autumn (July-September). Chla, thermal and chla-fronts patterns were generally more intense in the high-use area than in the rest of the western Mediterranean, highlighting its enhanced productivity throughout the year, first by a stronger spring bloom, then during summer-winter by stronger thermal fronts. Note that the periodicity of these productivity indicators and the thermocline also correlates well with seasonal changes in the vertical behaviour of ABFT (clusters and diel patterns), presented earlier. 

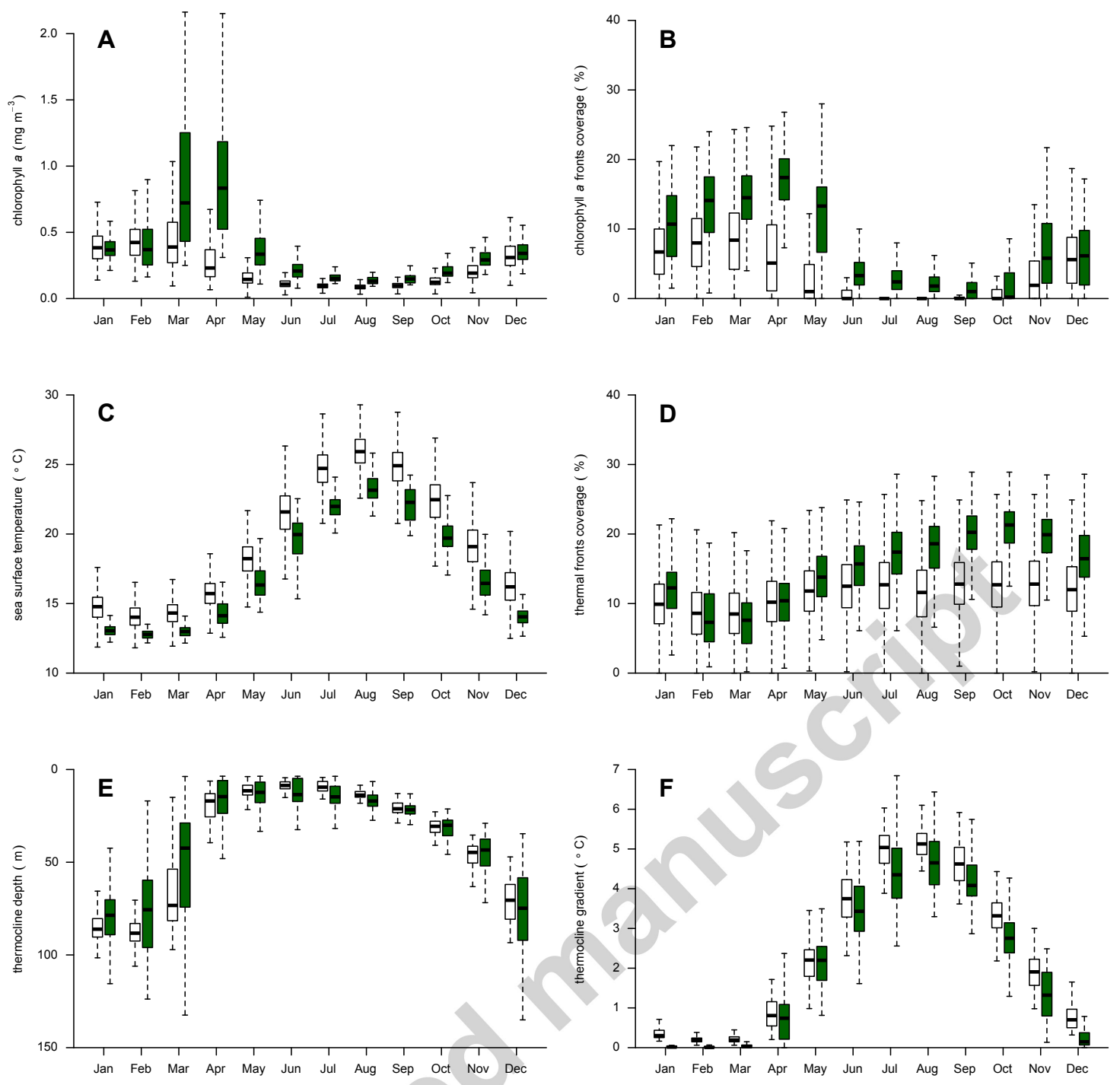

Figure 10 Monthly trends of different oceanographic parameters (A: chla; B: chla front frequencies; C: SST; D: thermal front frequencies; $E$ : thermocline depth; $F$ : thermocline gradient) based on their average daily estimates for the western Mediterranean (white) and the ABFT high-use area (green). SST, chla and related fronts were derived from satellite data. Thermocline estimates ( $E$ and $F$ ) are model based, of which only results for the first SYMPHONIE model are shown (model years 2007-2011), as the second model does not cover the entire western Mediterranean.

\subsubsection{Modelling surfacing behaviour}

The best GAMs for the recovered tag and the pooled data from 10 PATs consistently indicated a significant influence of the horizontal position and the gradient of the thermocline on the surface presence of ABFT in the western Mediterranean Sea (Fig. S6 and 11). The multiple-tag model suggested an additional effect of fish size. The best model of the recovered tag explained $56 \%$ of the deviance $\left(R^{2}=0.5\right)$, whereas the 
performance of the best multi-tag model was slightly weaker (36\% of deviance explained; $\left.R^{2}=0.33, \mathrm{n}=970\right)$. Both models suggest a non-linear, convex shaped effect of the thermocline gradient on the surface presence of ABFT, as well as higher levels of surface presence in the area of the Gulf of Lions and adjacent waters to the south.
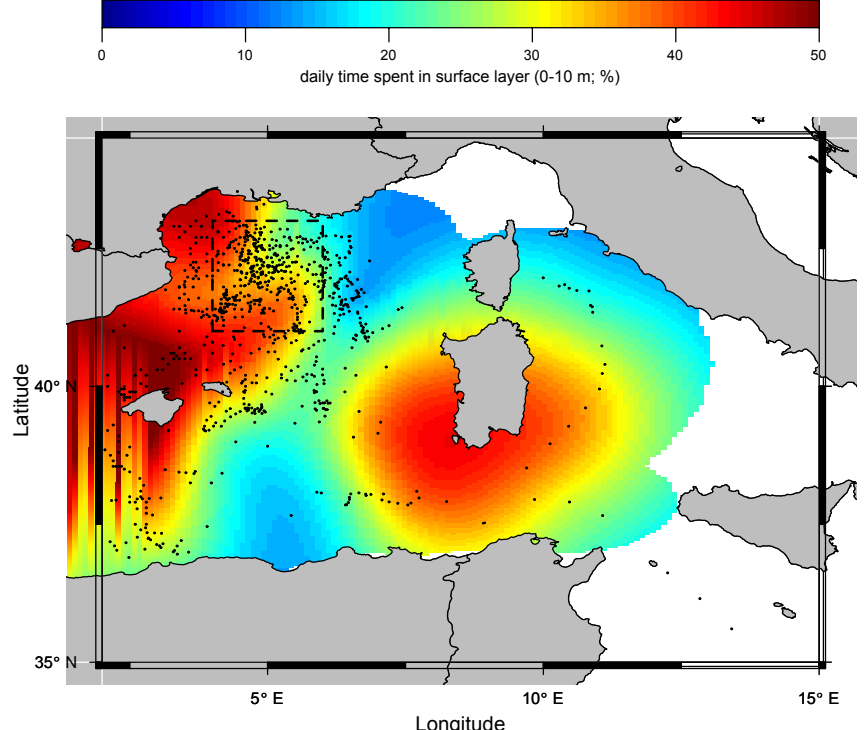
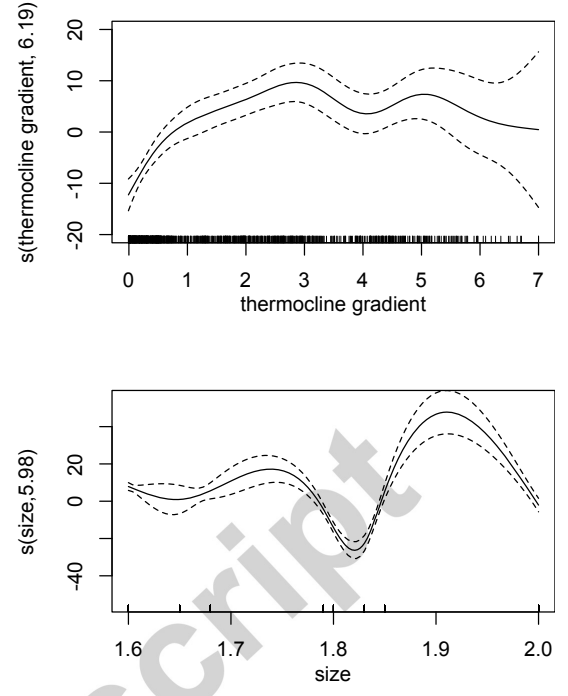

Figure 11 Predicted surface presence of ABFT in the western Mediterranean (left) based on 10 PAT tags (\#92108, \#92113, \#92114, \#92116, \#34273, \#61964, \#61969, \#73423, \#112623, \#112626) with more than 60 days of TAD data $(n=970)$, with corresponding estimated geopositions (dots) and the high-use area (black rectangle) of ABFT detected by Fromentin and Lopuszanski (2013), as well as the variables "thermocline gradient" (grad_mean) and size (in meters) against their respective smoothing functions. For model diagnostics please see Tab. S2 and Fig. S4.

\section{Discussion}

In this study, we examined the vertical and horizontal behaviour of ABFT in the western Mediterranean Sea in relation to oceanographic conditions based on archival tagging data from 36 early mature ABFT (162 days of high resolution depth time series data, 1643 days of depth summary data, 4773 daily geolocation estimates). Based on a hierarchical clustering method, we could identify four principle types of daily vertical behaviour, representing surface and subsurface orientation, moderate and deep diving behaviour. These clusters showed seasonal changes in their frequencies and correlated with the seasonal changes in the thermal stratification, with surface behaviour being less frequent during unstratified periods (winter). Depth time series data confirmed these results, and further indicated site specific differences in vertical behaviour. Moreover, long and continuous depth time series data from one recovered tag demonstrated that deep diving behaviour of ABFT partly represents unusual deep and long spike dives in 
the presence of thermal fronts. An additional analysis on the specific oceanographic characteristics of a year-round high-use area of ABFT, located to the south of the Gulf of Lions, revealed higher signatures of productivity indicators (chla, and strong thermal and chla fronts) in this area, suggesting it represents an important feeding ground for ABFT. Such specific oceanographic structures are also recurrent over time, which could explain the homing behaviour depicted by Fromentin and Lopuszanski (2013). These results provide important information for ABFT management on the habitat use of apparently resident $A B F T$ in the western Mediterranean.

\section{Vertical behaviour}

Daily TAD data from 8 years of tag deployment (1643 days) allowed us to identify four distinct clusters of vertical behaviour, representing surface and subsurface orientation, moderate and deep diving behaviour. These clusters can be easily reproduced and applied to new datasets as our clustering algorithm is based on a hierarchical clustering scheme. Still, care must be taken in the interpretation of the clusters as daily TAD profiles can be composed of different vertical behaviour types. Such mixtures can be identified by using depth time series data or TAD profiles of higher resolution. For example, deep diving behaviour of the recovered tag \#92113 during September 2010, was composed of deep and long spike dives and followed by periods of surface orientation. The latter appeared to be an important component of all four clusters (on average comprising at least $25 \%$ or $6 \mathrm{~h}$ per day in all clusters). However, our results indicate that the surface orientation (cluster) commonly decreases in dominance from summer to winter. By contrast, dives to moderate depths increase in frequency from summer to winter, coinciding with the breakdown of the thermal stratification. Depth time series data confirms this seasonal switch of ABFT in the western Mediterranean from surface orientation to deeper waters (Fig. 9) and further suggests an associated inversion in diel vertical behaviour, with higher surface presence during the day in summer vs. night in winter. Similar changes in the vertical behaviour of $A B F T$, related to seasonal changes in the thermal stratification of the water column, have been described for ABFT in the North Atlantic (Walli et al., 2009; Galuardi and Lutcavage, 2012). Walli et al. (2009) found a correlation between the daily average diving depth of ABFT and thermocline depth throughout the North Atlantic $\left(R^{2}=0.72\right)$, based on 8986 days of recovered time series data from 44 archival tags. In our study, accurate measures of the daily average depth of ABFT were only available for one recovered tag, which did not show such a strong correlation to thermocline depth $\left(R^{2}=0.12, \mathrm{p}>0.1, \mathrm{n}=162\right)$. The GAM results showed that the surface orientation of this fish was significantly influenced by the gradient of the thermocline, but also by the 
horizontal position of the fish ( $57 \%$ of deviance explained; $R^{2}=0.51$ ). The GAMs on pooled data from several tags performed less well, generally indicating additional effects by the fish size on ABFT surface behaviour ( $43 \%$ of deviance explained; $R^{2}=0.37$ ). In summary, vertical behaviour in the western Mediterranean appears to be more complex than in the North Atlantic. Kitagawa (2013) suggested that moderate diving behaviour of Pacific bluefin tuna Thunnus orientalis (PBFT) increases in frequency during periods of lower food availability in the surface waters. Changes in the food availability could therefore contribute to the seasonality of ABFT vertical behaviour, apart from thermal stratification, but also explain parts of the variability in our data set, assuming a more scattered distribution of prey organisms in the Mediterranean. Interestingly, under such circumstances, PBFT do not entirely switch to deeper waters, where food resources are probably more persistent throughout the year, but rather conduct short and repeated dives through the thermocline, likely in order to meet their thermo-regulatory demands. We made similar observations of ABFT vertical diving behaviour, particularly during winter. By contrast, Kitagawa et al. (2007b) related the higher surface orientation and less frequent dives of PBFT through the thermocline to enhanced food resources in the surface waters during summer Kitagawa et al. (2007b). Food selection of ABFT is generally very variable as tunas are opportunistic feeders (de la Serna et al., 2012). However, during summer ABFT are often seen surface feeding on anchovies and sardines in the Gulf of Lions, despite the usually weak thermal stratification in this area, a fact that is used to assess ABFT abundance through aerial surveys (Bauer et al., 2015a). This is also reflected in the dominance of these epipelagic prey species in stomach samples of locally caught ABFT. Accordingly, anchovies and sardines account together for $>$ $80 \%$ of the tuna diet (biomass and numbers) in this area $(n=118$; Van Beveren et al., 2017). Similar findings on ABFT diet have been reported from the nearby Ligurian Sea (Orsi Relini et al., 1995). Food availability, or more precisely the abundance and vertical distribution of prey organisms, may therefore induce additional effects on ABFT vertical behaviour, irrespective of the thermal stratification, similar to PBFT (Kitagawa et al., 2007b).

Deep diving behaviour of ABFT, indicated by cluster 4, was found year-round, including during periods of strong thermal stratification, although it was more common during spring at higher productivity levels. While no data was available to examine in detail the underlying dive patterns during the first part of the year, the available depth time series of our recovered tag (\#92113; Fig. S3) demonstrated for periods of strong stratification that this behaviour is, at least partly, related to very deep and long lasting spike dives. Spike dives represent a common behaviour of many large pelagic fish around twilight, 
including tunas, sharks and swordfish (Carey and Robison, 1981; Carey et al., 1990; Block et al., 1997; Kitagawa et al., 2004; Willis et al., 2009), which probably share the same motivation. As possible explanations, Gunn and Block (2001) suggested 1) locating the lower depth of the mixed layer, 2) surveying prey fields, 3) mapping the geomagnetic field for navigation, and 4) examining the thermo-physical water column structure". Willis et al. (2009) developed the idea of a possible navigational role, considering that many fishes are known to possess physical structures that function much like a magnetic compass. They argued that deep spike dives $(\sim 500 \mathrm{~m})$ could provide fish with a more accurate picture of the local magnetic field undisturbed by the noise of the surface current. Moreover, Willis et al. (2009) noted that the magnetic intensity is highest worldwide around the time of twilight and thus most suitable for regular magnetic mapping. As the different hypotheses on the driving factors of spike dives are not mutually exclusive, Willis et al. (2009) further speculated that the rapid descents or ascents of spike dives may also represent a method to inspect the thermal stratification and/or to identify the strength and direction of the surface current, as proposed by Gunn and Block (2001). Spike dives of less than $1 \mathrm{~h}$ were not uncommon in the depth time series of our recovered tag (\#92113; Fig. S3) similar to the regular spike dive durations of the closely related southern bluefin tuna Thunnus maccoyii described by Willis et al. (2009). However, during summer single spike dives of this fish could last up to $6 \mathrm{~h}$ with descents to depths of $>600 \mathrm{~m}$. The majority of these spike dives appeared to be related to the occurrence of a strong thermal front which this fish followed for several days. This "Pyrenees front" is a frequent feature in the northwestern Mediterranean, located perpendicular to the Catalan coast at the southeastern edge of the Gulf of Lions (López García et al., 1994). It is formed by the shadowing effect of the Pyrenees over the Mistral jet as noted by Pascual et al. (2002), with a strong thermal gradient to the colder waters of the Gulf of Lions during such wind events (Fig. 4). Such persistent ocean fronts often showed increased levels of biological productivity that attract top predators including tunas (Royer et al., 2004; Doniol-Valcroze et al., 2007; Kitagawa et al., 2007a; Walli et al., 2009). These deep and long lasting spike dives could therefore also represent a specific feeding behaviour of ABFT, by which the fish follow the diel vertical migrations of potential prey organisms in the deep scattering layer. Such a behaviour would further support the hypothesized opportunistic component in the vertical behaviour of ABFT, irrespective of the thermocline depth. Interestingly, Aranda et al. (2013) observed similar diving behaviour of ABFT in the nearby Balearic Sea, also during periods of surface orientation and strong thermal stratification, although rather more sporadically than during a sequence of several days. 


\subsubsection{Horizontal behaviour}

Oceanographic data of the western Mediterranean revealed higher levels of productivity indicators (chla and ocean fronts) for the high-use area of ABFT, south of the Gulf of Lions, suggesting its use as a foraging ground. In fact, tagging data from fin whales Balaenoptera physalus showed that this area is also very attractive to other large pelagic predators, despite their different feeding habits (Bentaleb et al., 2011). Thermal fronts in this area were particularly frequent during autumn, as a result of strong seasonal NW-N winds (Mistral and Tramontane) that cool the shelf waters of the Gulf of Lions. By contrast, chla levels, and thus the frequency of corresponding fronts, were higher during spring (February-March). Considering the rather low productivity of Mediterranean waters, food resources of ABFT are likely to be more scattered in the Mediterranean than in the North Atlantic, making the northwestern Mediterranean a unique feeding hotspot for ABFT. The constant recurrence of this productivity hotspot may explain the homing behaviour of ABFT to this area. In fact, ABFT are present in the high-use area throughout the year, particularly during summer-autumn, when thermal stratification is strong (Fromentin and Lopuszanski, 2013). This observation is likely linked to the local seasonal migrations of sardines and anchovies to coastal waters during summer that ABFT appear to follow (Fig. 8; UNEP MAP-RAC/SPA, 2013; Saraux et al., 2014). In this context, our results underline the importance of the Gulf of Lions as a pronounced surface feeding area of ABFT, indicated by the elevated levels of surface orientation, but also suggest spatial dependencies of ABFT vertical behaviour. It can further be hypothesized that effects of the apparently stronger spring bloom on such small pelagic fish, and thus the presence of ABFT, are not immediate, but delayed by the turnover rates between trophic levels of the food chain (Lloret et al., 2004). Mesopelagic food resources, such as squid, might be less linked to the productivity cycle in this canyon-rich area and thus more persistent throughout the year. The higher dispersal of ABFT in the first half of the year might also be influenced by the reproduction cycle of ABFT, i. e. migrations to the spawning sites in May-July (Fromentin and Powers, 2005).

Taken together, the high productivity of epipelagic and mesopelagic communities in the waters around the Gulf of Lions, induced by the specific oceanographic and topographic characteristics of this area, provide suitable year-round feeding conditions for a resident ABFT population. Seasonal changes in the horizontal and vertical behaviour of ABFT appear to be mainly triggered by the prey abundance of epipelagic fish, such as sardines and anchovies, in accordance to previous findings on ABFT and PBFT (Kitagawa et al., 2007b; Schick and Lutcavage, 2009). 


\subsubsection{Relevance of findings for ABFT aerial surveys}

The results of this study provide important information for aerial survey programs aiming at assessing ABFT abundance (Eveson et al., 2012; Bauer et al., 2015a). Accordingly, the suitability of potential survey regions and periods, defined by a high area and surface presence of tunas, depends on the thermal stratification of the water column and the availability of epipelagic food resources, which is linked to the regional productivity. In case of annual ABFT aerial surveys conducted in the Gulf of Lions, they confirm the suitability of the selected area and period (autumn). The relevance of these aspects is supported by results from other studies, indicating their plausibility also for related species (Kitagawa et al., 2007b; Walli et al., 2009; Galuardi and Lutcavage, 2012). Similar tagging programs should therefore be conducted to identify other areas suitable for ABFT aerial surveys. By contrast, additional depth time series data is needed to reliably assess the fraction and constancy of ABFT visible during the survey programs in the Gulf of Lions (i.e. during the actual survey hours). 


\section{*References}

Alemany F, Quintanilla L, Velez-Belchí P, García A, Cortés D, Rodríguez JM, Fernández de Puelles ML et al. (2010) Characterization of the spawning habitat of Atlantic bluefin tuna and related species in the Balearic Sea (western Mediterranean). Progress in Oceanography 86:21-38. doi: 10.1016/j.pocean.2010.04.014

Aranda G, Abascal FJ, Varela JL, Medina A. (2013) Spawning behaviour and postspawning migration patterns of Atlantic bluefin tuna (Thunnus thynnus ) ascertained from satellite archival tags. PloS ONE 8:e76445. doi: 10.1371/journal.pone.0076445

Basson M, Farley JH. (2014) A standardised abundance index from commercial spotting data of southern bluefin tuna (Thunnus maccoyii): Random effects to the rescue. PLoS ONE 9:e116245. doi: 10.1371/journal.pone.0116245

Bauer R. (2017) RchivalTag: Analyzing Archival Tagging Data. R package version 0.0.2. https : //cran.r-project.org/package=RchivalTag

Bauer RK. (2016) oceanmap: A Plotting Toolbox for 2D Oceanographic Data. R package version 0.0.3. https://cran. $r$-project. org/package=oceanmap

Bauer RK, Bonhommeau S, Brisset B, Fromentin JM. (2015a) Aerial surveys to monitor bluefin tuna abundance and track efficiency of management measures. Marine Ecology Progress Series 534:221-234. doi: 10.3354/meps11392

Bauer RK, Forget F, Fromentin JM. (2015b) Optimizing PAT data transmission - assessing the accuracy of temperature summary data to estimate environmental conditions. Fisheries Oceanography 24:533-539. doi: 10.1111/fog.12127

Bauer RK, Fromentin JM, Demarcq H, Brisset B, Bonhommeau S. (2015c) Co-occurrence and habitat use of fin whales, striped dolphins and Atlantic bluefin tuna in the Northwestern Mediterranean Sea. PLoS ONE 10:e0139218. doi: 10.1371/journal.pone.0139218

Bentaleb I, Martin C, Vrac M, Mate B, Mayzaud P, Siret D, de Stephanis R et al. (2011) Foraging ecology of Mediterranean fin whales in a changing environment elucidated by satellite tracking and baleen plate stable isotopes. Marine Ecology Progress Series 438:285-302. doi: 10.3354/meps09269

Bivand R, Lewin-Koh N. (2015) maptools: Tools for reading and handling spatial objects. R package version 0.8-36. http://cran.r-project.org/package=maptools 
Block BA, Keen JE, Castillo B, Dewar H, Freund EV, Marcinek DJ, Brill RW et al. (1997) Environmental preferences of yellowfin tuna (Thunnus albacares) at the northern extent of its range. Marine Biology 130:119-132. doi: 10.1007/s002270050231

Block BA, Teo SLH, Walli A, Boustany A, Stokesbury MJW, Farwell CJ, Weng KC et al. (2005) Electronic tagging and population structure of Atlantic bluefin tuna. Nature 434:1121-1127

Brill RW, Lutcavage ME. (2001) Understanding environmental influences on movements and depth distributions of tunas and billfishes can significantly improve population assessments. American Fisheries Society Symposium 25:179-198

Carey FG, Robison BH. (1981) Daily patterns in the activities of swordfish Xiphias gladius, observed by acoustic telemetry. Fishery Bulletin 79:277-292

Carey FG, Scharold JV, Kalmijn A. (1990) Movements of blue sharks (Prionace glauca) in depth and course. Marine Biology 106:329-342. doi: 10.1007/BF01344309

Cermeño P, Quílez-Badia G, Ospina-Alvarez A, Sainz-Trápaga S, Boustany AM, Seitz AC, Tudela $S$ et al. (2015) Electronic tagging of Atlantic bluefin tuna (Thunnus thynnus, L.) reveals habitat use and behaviors in the Mediterranean Sea. Plos ONE 10:e0116638. doi: $10.1371 /$ journal.pone.0116638

de la Serna JM, Godoy MD, Olaso I, Zabala J, Majuelos E, Báez JC. (2012) Preliminary study on the feeding of bluefin tuna (Thunnus thynnus) in the Mediterranean and the Strait of Gibraltar area. Collective Volume of Scientific Papers ICCAT 68:115-132

Doniol-Valcroze T, Berteaux D, Larouche P, Sears R. (2007) Influence of thermal fronts on habitat selection by four rorqual whale species in the Gulf of St. Lawrence. Marine Ecology Progress Series 335:207-216. doi: 10.3354/meps335207

Druon JN, Panigada S, David L, Gannier A, Mayol P, Arcangeli A, Cañadas A et al. (2012) Potential feeding habitat of fin whales in the western Mediterranean Sea: an environmental niche model. Marine Ecology Progress Series 464:289-306. doi: $10.3354 / \operatorname{meps} 09810$

Eveson P, Farley J, Bravington M. (2012) The aerial survey index of abundance: updated analysis methods and results for the 2011/12 fishing season. CCSBT-ESC/1208/16, 17th meeting of the Scientific Committee, Commission for the Conservation of Southern Bluefin Tuna, 27-31 August 2012, Tokyo, Japan. 25 pp. 
Farrugio H, Duclerc J, Tournier H. (1977) La pêche du thon rouge au filet tournant le long des côtes françaises de Méditerranée. Science et Pêche 268:1-12

Fiedler PC. (2010) Comparison of objective descriptions of the thermocline. Limnology and Oceanography: Methods 8:313-325. doi: 10.4319/lom.2010.8.313

Fromentin JM, Bonhommeau S, Arrizabalaga H, Kell LT. (2014a) The spectre of uncertainty in management of exploited fish stocks: The illustrative case of Atlantic bluefin tuna. Marine Policy 47:8-14. doi: 10.1016/j.marpol.2014.01.018

Fromentin JM, Lopuszanski D. (2013) Migration, residency, and homing of bluefin tuna in the western Mediterranean Sea. ICES Journal of Marine Science 71:510-518. doi: 10.1093/icesjms/fst157

Fromentin JM, Powers JE. (2005) Atlantic bluefin tuna: population dynamics, ecology, fisheries and management. Fish and Fisheries 6:281-306. doi: 10.1111/j.14672979.2005.00197.x

Fromentin JM, Reygondeau G, Bonhommeau S, Beaugrand G. (2014b) Oceanographic changes and exploitation drive the spatio-temporal dynamics of Atlantic bluefin tuna (Thunnus thynnus). Fisheries Oceanography 23:147-156. doi: 10.1111/fog.12050

Galuardi B, Lutcavage M. (2012) Dispersal routes and habitat utilization of juvenile Atlantic bluefin tuna, Thunnus thynnus, tracked with mini PSAT and archival tags. PLoS ONE 7:e37829. doi: 10.1371/journal.pone.0037829

Gunn J, Block B. (2001) Advances in acoustic, archival and satellite tagging of tunas. In Tuna: Physiology, ecology, and evolution, edited by Block BA, Stevens ED. Academic Press, San Diego. pp. 167-244

Hu ZY, Doglioli AM, Petrenko AA, Marsaleix P, Dekeyser I. (2009) Numerical simulations of eddies in the Gulf of Lion. Ocean Modelling 28:203-208

Kitagawa T. (2013) Behavioral ecology and thermal physiology of immature Pacific bluefin tuna. In Physiology and ecology of fish migration, edited by Ueda $\mathrm{H}$, Katsumi T. CRS Press, Taylor \& Francis Group. Chapter 7, pp. 152-178

Kitagawa T, Boustany AM, Farwell CJ, Williams TD, Castleton MR, Block BA. (2007a) Horizontal and vertical movements of juvenile bluefin tuna (Thunnus orientalis) in relation to seasons and oceanographic conditions in the eastern Pacific Ocean. Fisheries Oceanography 16:409-421. doi: 10.1111/j.1365-2419.2007.00441.x 
Kitagawa T, Kimura S, Nakata H, Yamada H. (2004) Diving behavior of immature, feeding Pacific bluefin tuna (Thunnus thynnus orientalis) in relation to season and area: the East China Sea and the Kuroshio-Oyashio transition region. Fisheries Oceanography 13:161-180. doi: 10.1111/j.1365-2419.2004.00282.x

Kitagawa T, Kimura S, Nakata H, Yamada H. (2007b) Why do young Pacific bluefin tuna repeatedly dive to depths through the thermocline? Fisheries Science 73:98-106. doi: 10.1111/j.1444-2906.2007.01307.x

Langfelder P, Zhang B, Horvath S. (2008) Defining clusters from a hierarchical cluster tree: The dynamic tree cut package for R. Bioinformatics 24:719-720. doi: 10.1093/bioinformatics/btm563

Lloret J, Palomera I, Salat J, Sole I. (2004) Impact of freshwater input and wind on landings of anchovy (Engraulis encrasicolus) and sardine (Sardina pilchardus) in shelf waters surrounding the Ebre (Ebro) River delta (north-western Mediterranean). Fisheries Oceanography 13:102-110. doi: 10.1046/j.1365-2419.2003.00279.x

López García MJ, Millot C, Font J, García-Ladona E. (1994) Surface circulation variability in the Balearic Basin. Journal of Geophysical Research 99:3285-3296. doi: 10.1029/93JC02114

Lutcavage M, Kraus S. (1997) Aerial survey of giant bluefin tuna, Thunnus thynnus, in the Great Bahama Bank, Straits of Florida, 1995. Fishery Bulletin 95:300-310

Lutcavage ME, Galuardi B, Lam TCH. (2013) Predicting potential Atlantic spawning grounds of Western Atlantic bluefin tuna based on electronic tagging results, 2002-2011. Collective Volume of Scientific Papers ICCAT 69:955-961

Marsaleix P, Auclair F, Floor JW, Herrmann MJ, Estournel C, Pairaud I, Ulses C. (2008) Energy conservation issues in sigma-coordinate free-surface ocean models. Ocean Modelling 20:61-89. doi: 10.1016/j.ocemod.2007.07.005

Meeus J. (1991) Astronomical algorithms. Willmann-Bell, Inc. 429 pp.

Newlands NK, Porcelli TA. (2008) Measurement of the size, shape and structure of Atlantic bluefin tuna schools in the open ocean. Fisheries Research 91:42-55. doi: 10.1016/j.fishres.2007.11.019

Nieto K, Demarcq H, McClatchie S. (2012) Mesoscale frontal structures in the Canary Upwelling System: New front and filament detection algorithms applied to 
spatial and temporal patterns. Remote Sensing of Environment 123:339-346. doi: 10.1016/j.rse.2012.03.028

Orsi Relini L, Garibaldi F, Cima C, Palandri G. (1995) Feeding of the swordfish, the bluefin and other pelagic nekton in the western Ligurian Sea. Collective Volume of Scientific Papers ICCAT 44:283-286

Pascual A, Buongiorno Nardelli B, Larnicol G, Emelianov M, Gomis D. (2002) A case of an intense anticyclonic eddy in the Balearic Sea (western Mediterranean). Journal of Geophysical Research 107:12 pp. doi: 10.1029/2001JC000913

Riccioni G, Stagioni M, Landi M, Ferrara G, Barbujani G, Tinti F. (2013) Genetic structure of bluefin tuna in the Mediterranean Sea correlates with environmental variables. PLoS ONE 8:e80105. doi: 10.1371/journal.pone.0080105

Roa-Pascuali L, Demarcq H, a. E. Nieblas. (2015) Detection of mesoscale thermal fronts from $4 \mathrm{~km}$ data using smoothing techniques: Gradient-based fronts classification and basin scale application. Remote Sensing of Environment 164:225-237. doi: $10.1016 /$ j.rse.2015.03.030

Rooker JR, Alvarado Bremer JR, Block BA, Dewar H, De Metrio G, Corriero A, Kraus RT et al. (2007) Life history and stock structure of Atlantic bluefin tuna (Thunnus thynnus). Reviews in Fisheries Science 15:265-310. doi: 10.1080/10641260701484135

Royer F, Fromentin JM, Farrugio H, Gaspar P. (2005a) Determining bluefin tuna habitat through frontal features in the Mediterranean Sea. Collective Volume of Scientific Papers ICCAT 58:1275-1284

Royer F, Fromentin JM, Gaspar P. (2004) Association between bluefin tuna schools and oceanic features in the western Mediterranean. Marine Ecology Progress Series 269:249-263. doi: 10.3354/meps269249

Royer F, Fromentin JM, Gaspar P. (2005b) A state-space model to derive bluefin tuna movement and habitat from archival tags. Oikos 109:473-484. doi: 10.1111/j.00301299.2005.13777.x

Saraux C, Fromentin JM, Bigot JL, Bourdeix JH, Morfin M, Roos D, Van Beveren E et al. (2014) Spatial structure and distribution of small pelagic fish in the Northwestern Mediterranean Sea. PloS ONE 9:e111211. doi: 10.1371/journal.pone.0111211 
Schick RS, Goldstein J, Lutcavage ME. (2004) Bluefin tuna (Thunnus thynnus) distribution in relation to sea surface temperature fronts in the Gulf of Maine (1994-96). Fisheries Oceanography 13:225-238. doi: 10.1111/j.1365-2419.2004.00290.x

Schick RS, Lutcavage ME. (2009) Inclusion of prey data improves prediction of bluefin tuna (Thunnus thynnus) distribution. Fisheries Oceanography 18:77-81. doi: 10.1111/j.1365-2419.2008.00499.x

Scott JM, Flittner GA. (1972) Behavior of bluefin tuna schools in the eastern north Pacific Ocean as inferred from fishermen's logbooks. Fishery Bulletin 70:915-927

Sibert JR, Lutcavage ME, Nielsen A, Brill RW, Wilson SG. (2006) Interannual variation in large-scale movement of Atlantic bluefin tuna (Thunnus thynnus) determined from pop-up satellite archival tags. Canadian Journal of Fisheries and Aquatic Sciences 63:2154-2166. doi: 10.1139/f06-114

Teo SLH, Boustany AM, Block BA. (2007) Oceanographic preferences of Atlantic bluefin tuna, Thunnus thynnus, on their Gulf of Mexico breeding grounds. Marine Biology 152:1105-1119. doi: 10.1007/s00227-007-0758-1

UNEP MAP-RAC/SPA. (2013) Fisheries in the Gulf of Lions. By Farrugio, H. Ed. RAC/SPA, Tunis. 79 pp.

Van Beveren E, Fromentin JM, Bonhommeau S, Nieblas AE, Metral L, Brisset B, Jusup $M$ et al. (2017) Prey predator interactions in the face of management regulations: changes in Mediterranean small pelagics are not due to increased tuna predation. Canadian Journal of Fisheries and Aquatic Sciences. doi: 10.1139/cjfas-2016-0152

Venables WN, Ripley BD. (2002) Modern Applied Statistics with S, 4th Edition. Statistics and Computing. Springer, New York, NY. doi: 10.1007/978-0-387-21706-2

Walli A, Teo SLH, Boustany A, Farwell CJ, Williams T, Dewar H, Prince E et al. (2009) Seasonal movements, aggregations and diving behavior of Atlantic bluefin tuna (Thunnus thynnus) revealed with archival tags. PloS ONE 4:e6151. doi: 10.1371/journal.pone.0006151

Willis J, Phillips J, Muheim R, Diego-Rasilla FJ, Hobday AJ. (2009) Spike dives of juvenile southern bluefin tuna (Thunnus maccoyii): A navigational role? Behavioral Ecology and Sociobiology 64:57-68. doi: 10.1007/s00265-009-0818-2

Wood S. (2006) Generalized Additive Models: An introduction with R. Chapman and Hall/CRC, Boca Rotan, FL, USA 
Table S1 Selected depth bin levels for Time-at-Depth histograms (TAD) per year and PAT tag. Depth bins shared by all tags were used to standardize TAD data. To simplify standardization of TAD profiles, depth bins of $1 \mathrm{~m}$ were considered as $0 \mathrm{~m}$. The underlying standardization algorithm is now implemented in the function "merge_histos" of the R-package "RchivalTag" (Bauer, 2017). 


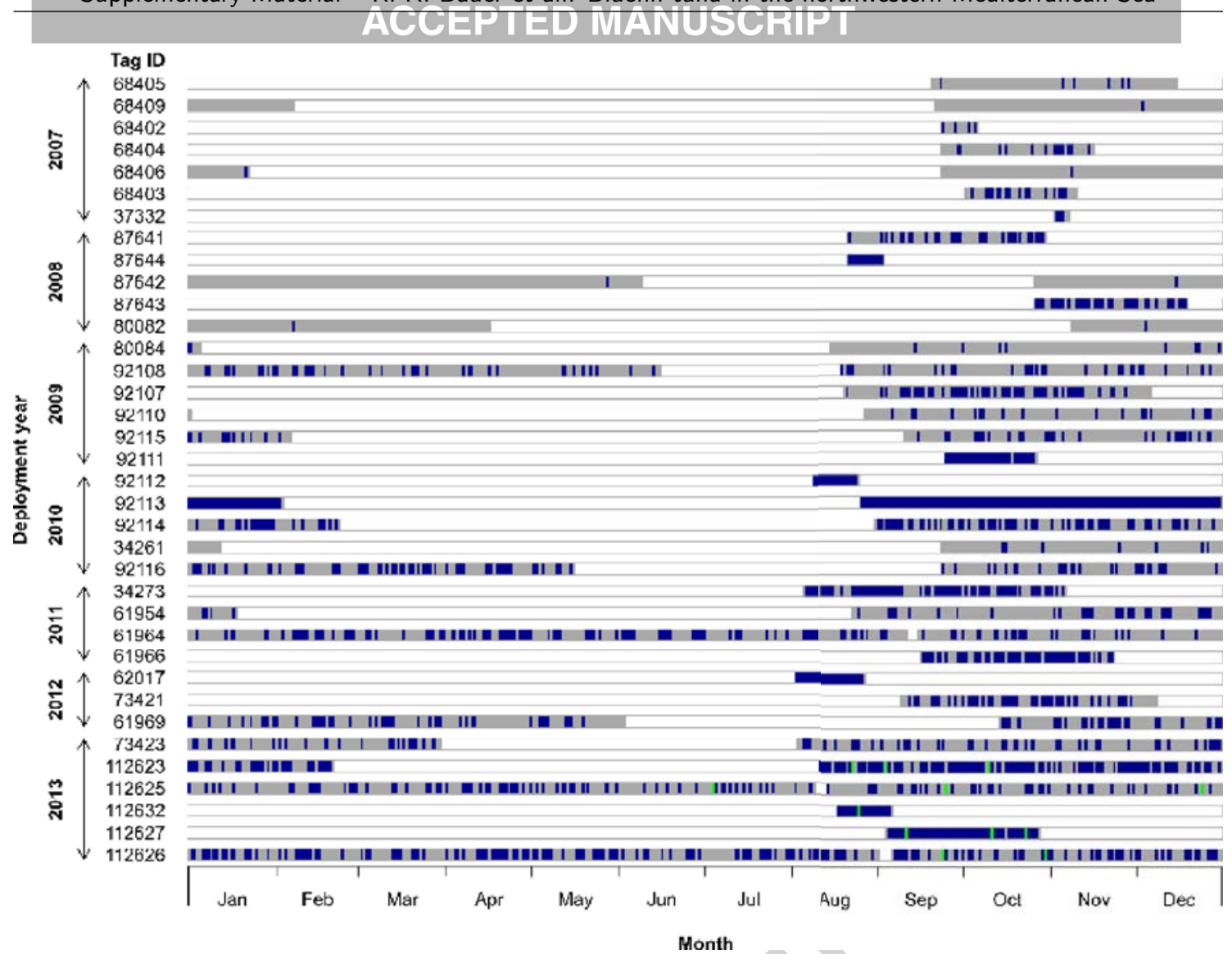

Figure S1 Temporal availability of transmitted (blue) and reconstructed (green) daily TAD profiles throughout the deployment period (grey) of each tag. Note that tags were generally deployed during August to November, so that the period from January to August corresponds to the subsequent year after tagging. 


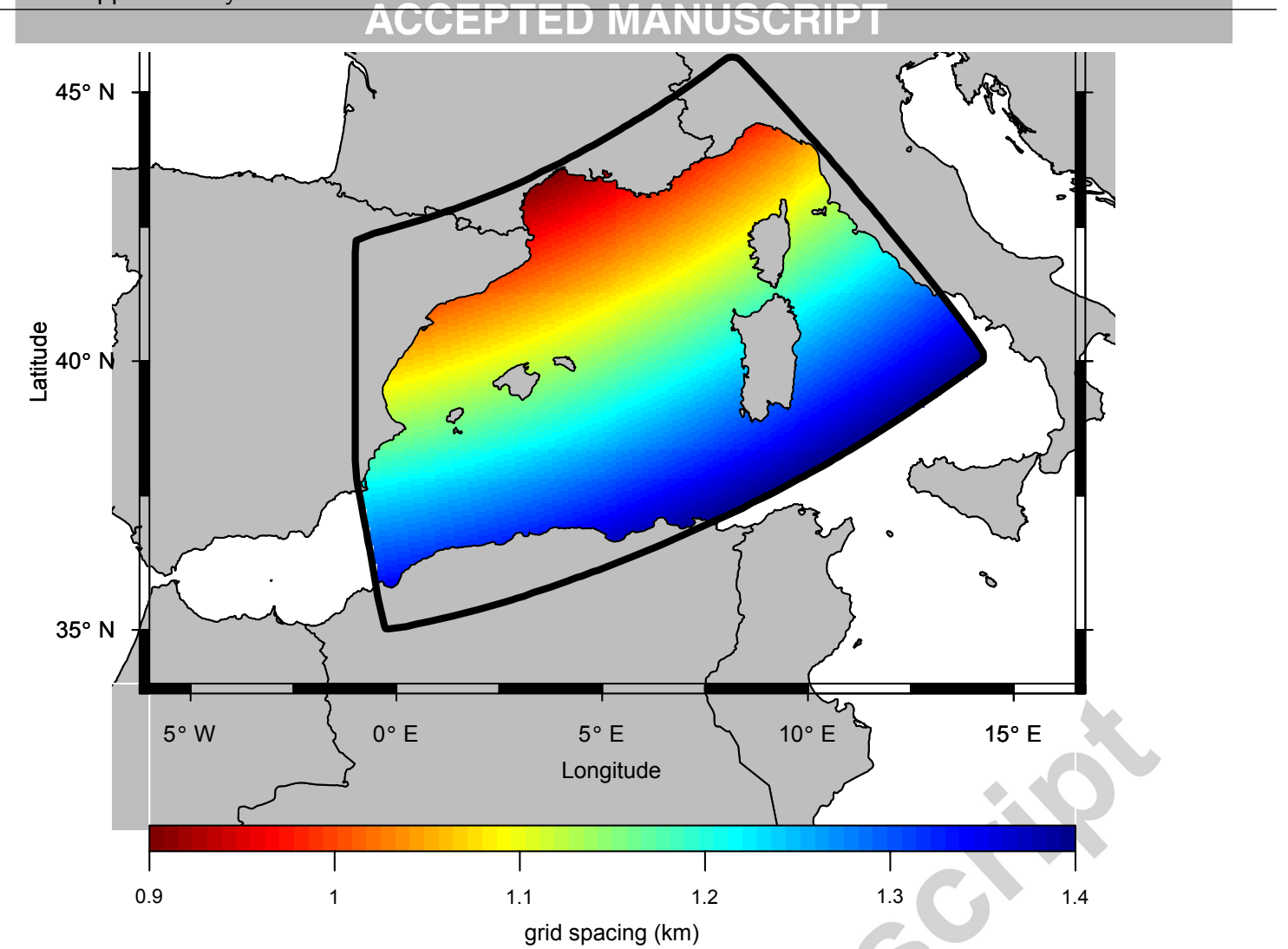

Figure S2 SYMPHONIE model region of the configuration used for the model years 2011-2015. The configuration used for model years prior to 2011 is not shown but covers the entire western Mediterranean with an almost regular grid spacing of around $10 \mathrm{~km}$. 



ACCEPIED IVIANUSCRIP
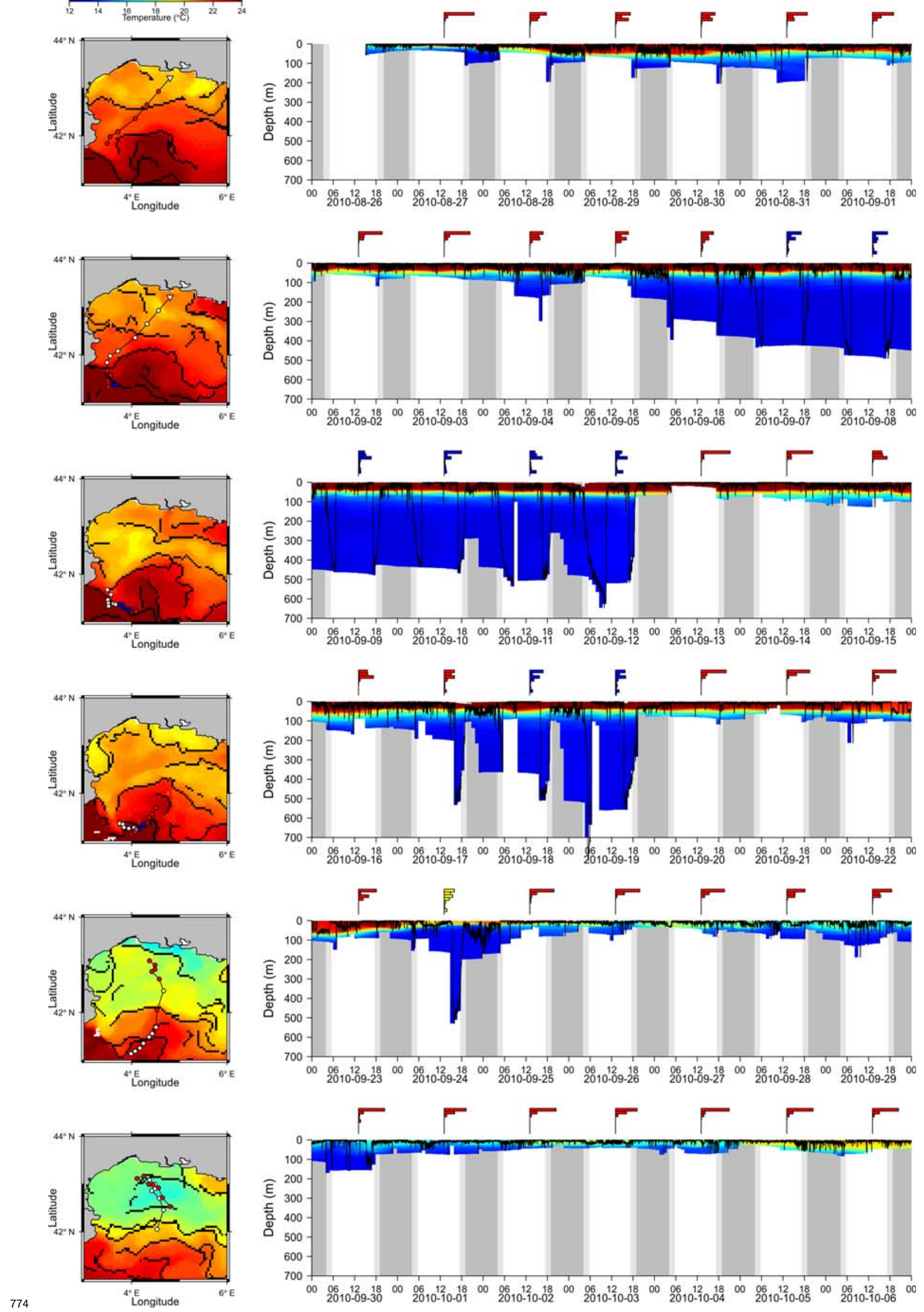

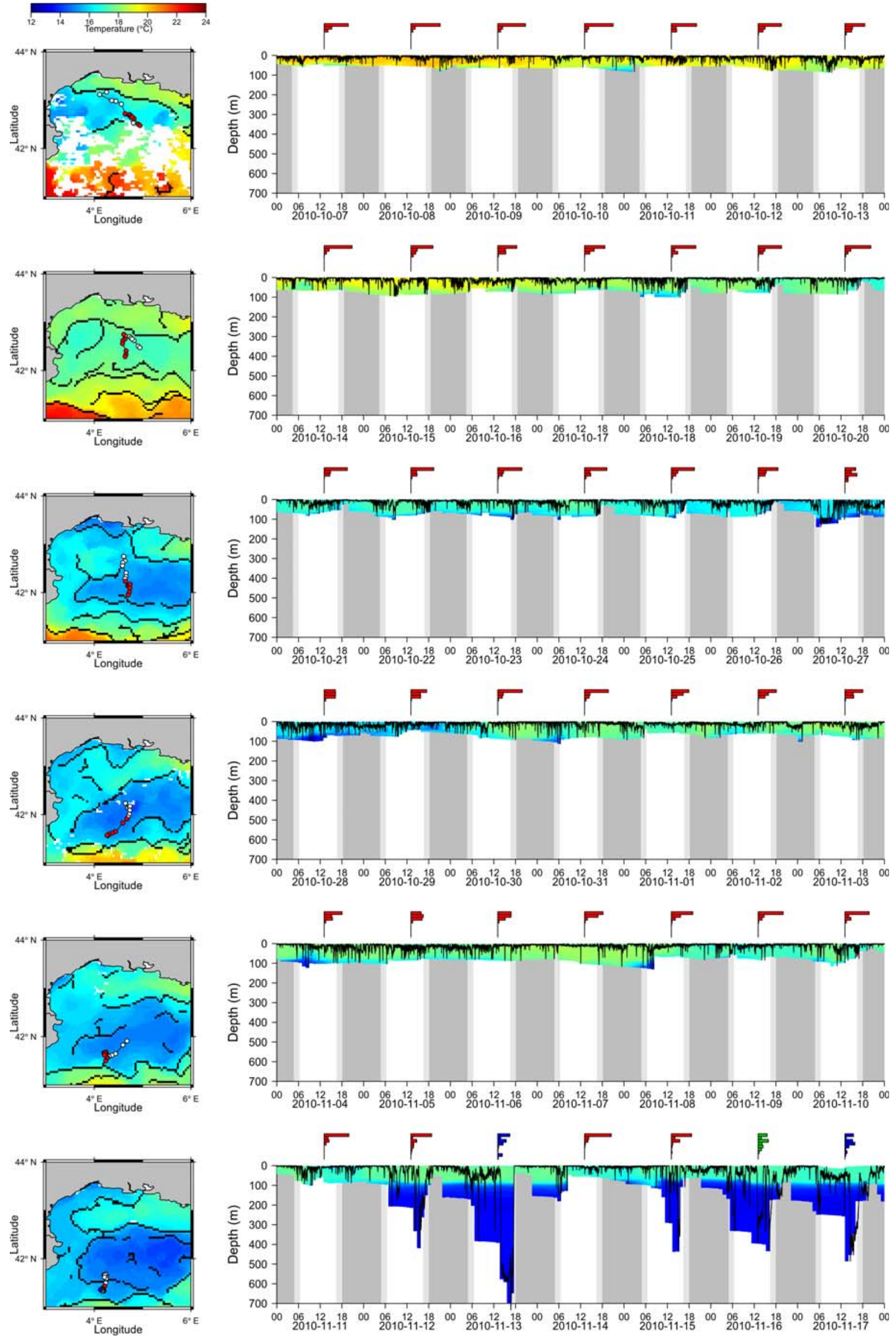



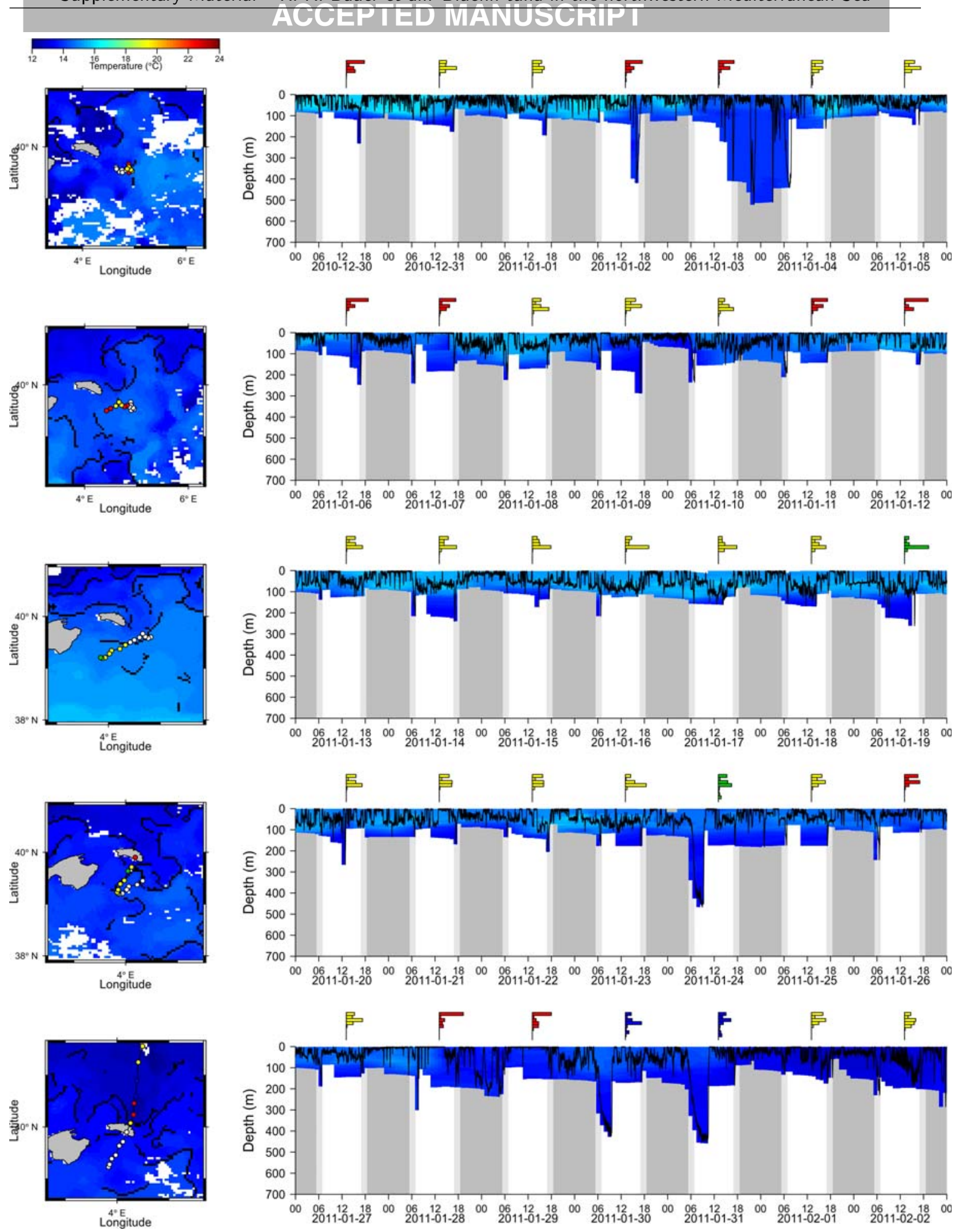

Figure S3 Left: Horizontal tracks of the MK10-tag \#92113 (left) with SST and thermal front locations (black lines) per week since tag deployment. Right: The corresponding depth time series data with daily TAD profiles and the water temperature fields experienced by the fish (interpolated). Daily geoloactions and TAD profiles of selected weeks are coloured according to their respective TAD-clusters. Geolocations of the previous week are indicated by white dots, the tagging position by a white inverted triangle. Night and twilight periods along the vertical tracks (right) are indicated in dark-grey and light-grey, respectively. Maps and time series plots were drawn using the functions "plotmap" and "plot_TS" of the R-packages "oceanmap" and "RchivalTag", respectively (Bauer, 2016, 2017). 


\section{$A C O=P$ ED MANOSORTP}

Table S2 Summary of the GAM on the surface presence of 10 PAT tags with more than 60 days of TAD data (\#92108, \#92113, \#92114, \#92116, \#34273, \#61964, \#61969, \#73423, \#112623, \#112626) deployed on ABFT in the northwestern Mediterranean.

Family: gaussian

Link function: identity

Formula:

field $~ s($ Lon, Lat $)+s($ grad_mean $)+s($ size, $k=7)$

Parametric coefficients:

Estimate Std. Error t value $\operatorname{Pr}(>|t|)$

(Intercept) $35.4645 \quad 0.5465 \quad 64.9<2 e-16$

Signif. codes: 0 '***, $0.001^{\prime} * *, 0.01$ '*, 0.05, , $0.1,, 1$

Approximate significance of smooth terms:

edf Ref.df $F$ p-value

s(Lon, Lat) $\quad 24.79227 .941 \quad 8.57<2 e-16 * * *$

s(grad_mean) $6.703 \quad 7.83012 .40<2 e-16 * * *$

s(size) $\quad 5.980 \quad 5.99929 .29<2 e-16 * * *$

$---$

Signif. codes: 0 '***' 0.001 '**' 0.01 '*' 0.05 '.' 0.1 , 1

$R-s q \cdot(\operatorname{adj})=0.337$ Deviance explained $=36.3 \%$

$\mathrm{GCV}=301.63$ Scale est. $=289.67 \quad \mathrm{n}=970$ 



Histogram of residuals

Response vs. Fitted Values
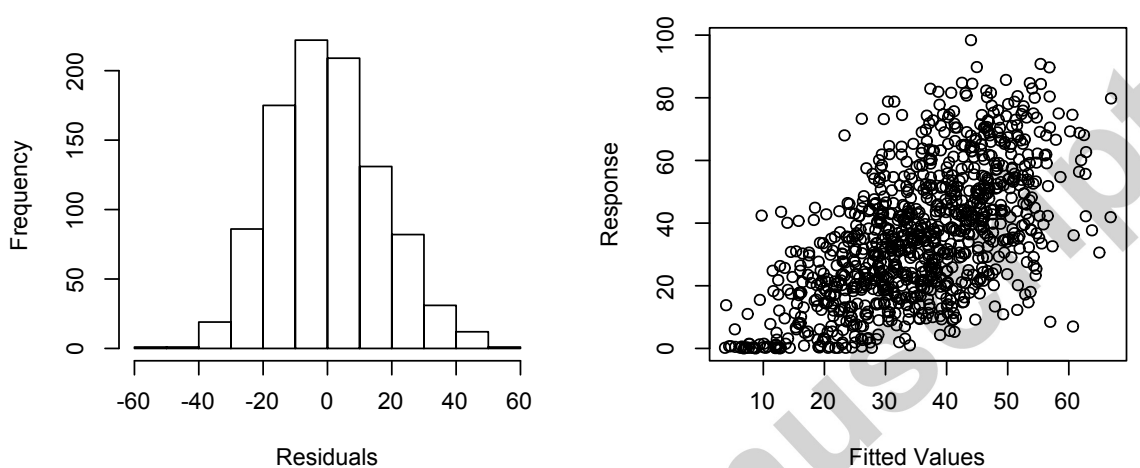

Figure S4 Diagnostic plots for the GAM on the surface presence of 10 PAT tags with more than 60 days of TAD data (\#92108, \#92113, \#92114, \#92116, \#34273, \#61964, \#61969, \#73423, \#112623, \#112626) deployed on ABFT in the northwestern Mediterranean. 


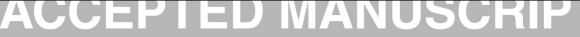

Table S3 Summary of the GAM on the surface presence of recovered tag \#92113.

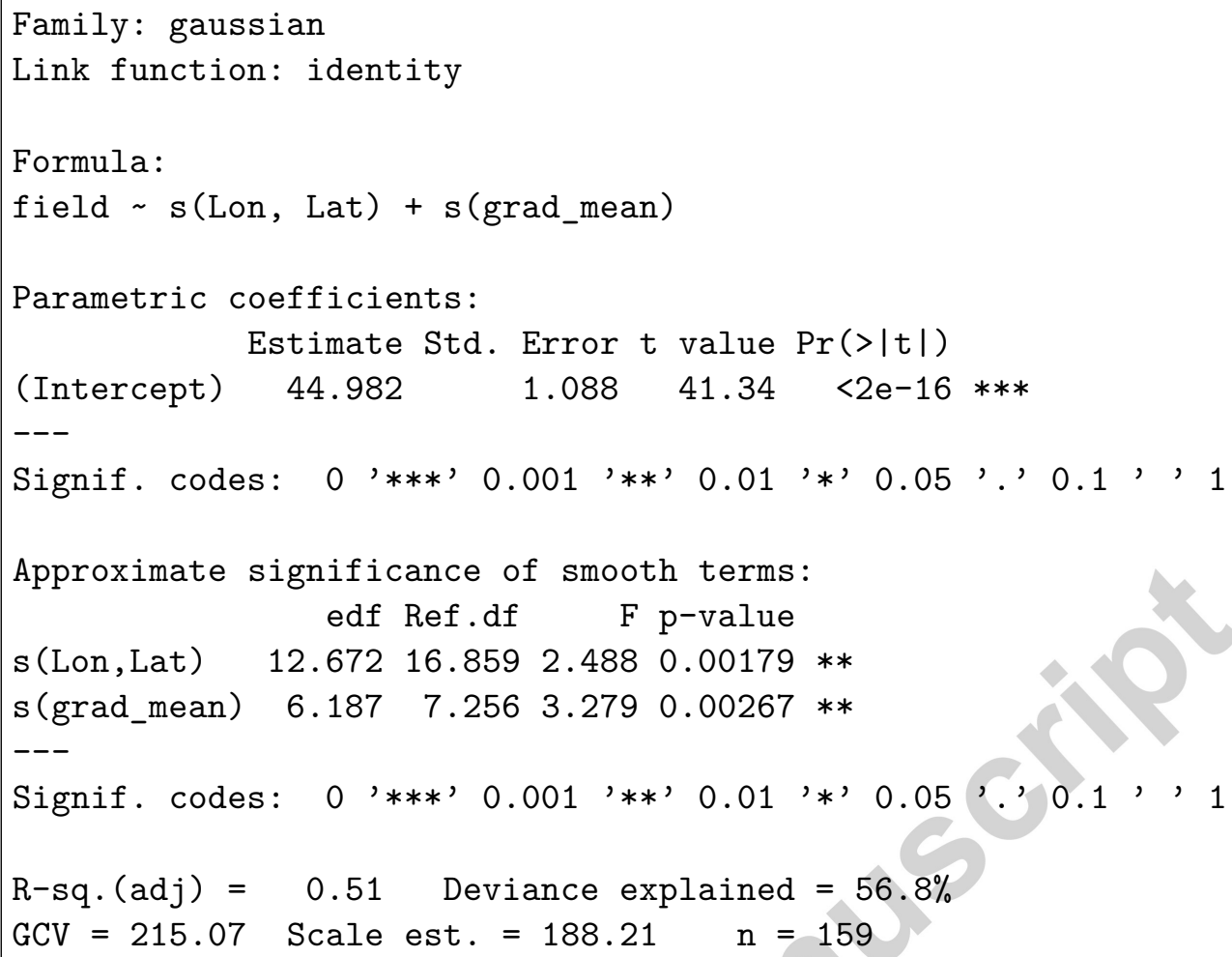






Histogram of residuals

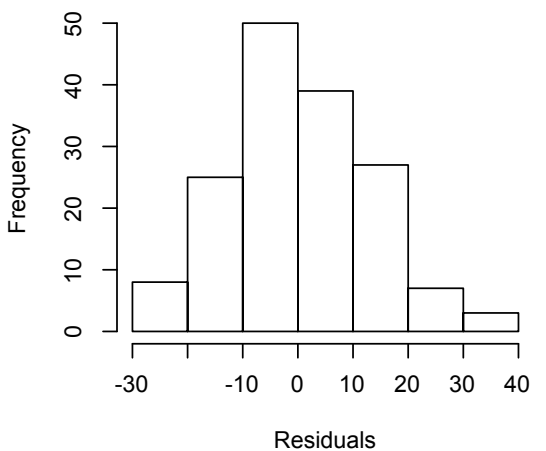

Resids vs. linear pred.

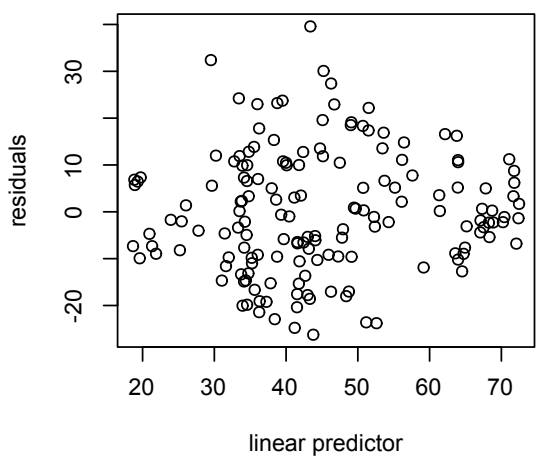

Response vs. Fitted Values

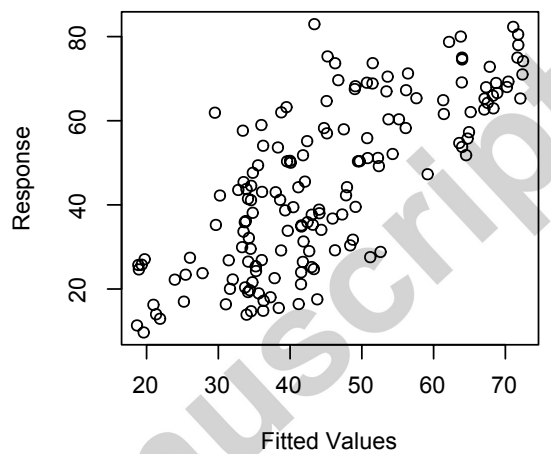

Figure S5 Diagnostic plots for the GAM on the surface presence of recovered tag \#92113
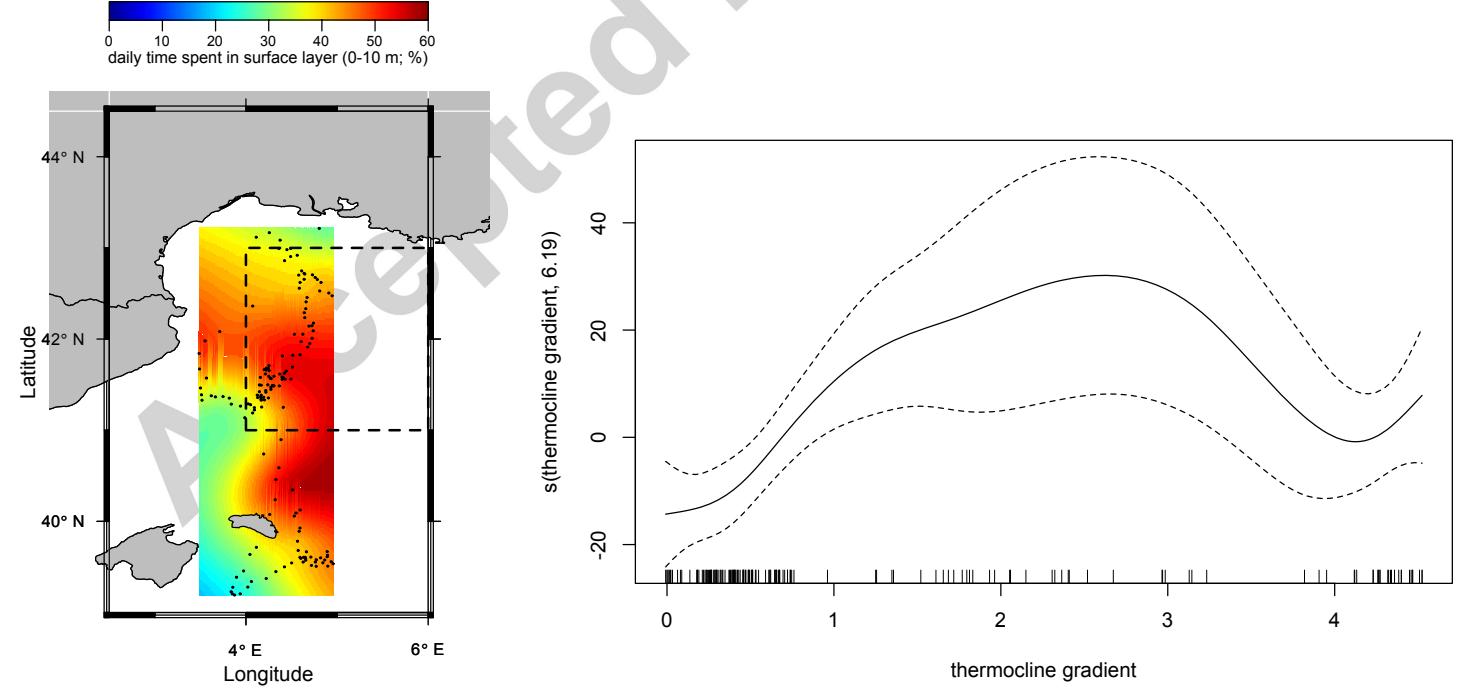

Figure S6 Predicted surface presence of tag \#92113 in the western Mediterranean (left), with its estimated geopositions (dots) and the high-use area (black rectangle) of ABFT detected by Fromentin and Lopuszanski (2013) in the northwestern Mediterranean, as well as the variable "thermocline gradient" (grad_mean) against its smoothing function. 